\title{
A New Strategy to Synthesis an Optimum Controllable HEN by using Fuzzy Analogical Gates
}

\author{
M.H.Hussein \\ Teaching Assistant \\ Chemical \\ Engineering \\ Department - High \\ Institute of \\ Engineering \\ Shorouk City
}

\author{
H.Moselhy \\ Associate Professor \\ Chemical \\ Engineering \\ Department - High \\ Institute of \\ Engineering \\ Shorouk City
}

\author{
S.Aly \\ Professor \\ Chemical and \\ Petroleum Refining \\ Engineering \\ Department - Suez \\ University
}

\author{
M. E. Awad \\ Assistant Professor \\ Chemical and Petroleum \\ Refining Engineering \\ Department - Suez \\ University
}

\begin{abstract}
This paper presents a new strategy to synthesis optimum controllable heat exchanger networks; the proposed strategy consists of four sequential steps: i) Quantification of index of structural controllability. ii) Exergy analysis and normalized irreversibility. iii) Thermal effectiveness of network. iv) Fuzzy analogical gates network and selection of the best weight index. Two analogical gates (symmetric and asymmetric) are employed. The symmetric gate (AND gate) inputs are the index controllability and thermal effectiveness. The asymmetric gate (Invoke gate) inputs are the output of the AND gate and the normalized irreversibility. The proposed method has been applied for two problems well-known in published literature. The results of these case studies show that the present strategy is both robust and accurate when the index of controllability is the same for different networks and it's to hard to decide the optimum controllable network, also, from the view point of exergy and thermal effectiveness.
\end{abstract}

\section{Keywords}

Controllability, Heat exchanger networks, Process synthesis, Exergy analysis, Thermal effectiveness, Irreversibility, Fuzzy analogical gates.

\section{INTRODUCTION}

Heat exchangers are commonly designed to operate under certain constant variables, such as: a given duty, constant inlet temperatures and fixed mass-flow rates. But, a normal process always has fluctuations that either affects the inlet temperatures or mass flow rates of the streams and then the initial assumptions are no longer applicable. So, when the network is already designed some corrective actions must be taken in order to preserve the operability of the process. Few published papers can be found regarding control strategies. Most information available about process control are mainly concerned with the design of the heat exchanger control system neglecting the effect of mass-flow rate variations on the value of the overall heat transfer coefficient. Various approaches are available for improving the structures of processes and their control performances Douglas [1]; McAvoy [2]; Shinskey [3]; Calandranis and Stephanopoulos[4]; Fisher et al. [5 and 6]. These approaches can be classified into two groups according to the type of formation used in integrating the process design and control. One group is based on steady-state characteristics of the process. The other group is based on the dynamic characteristics of the process and requires an approximate or complete dynamic model of the process. While there is substantial development in the former, it is not the case for the latter, which appears to be a fertile ground for further research process design and control are essentially hierarchical or sequential. This would give rise to time-consuming and tedious procedures requiring extensive iteration. At every iterative step, the structure of the process optimally designed in the first step is often altered and rendered non optimal in satisfying the control-related criteria, such as controllability and robustness, in the second step; these procedures are indeed passive Huang and Fan [7].

Among the control-related criteria, the controllability is of the utmost importance. It is highly desirable; therefore, that the controllability be taken into account at the earliest possible stage in the process synthesis phase to effectively integrate the design of a process and that of its control system. Nevertheless, very little attention has been paid to this type of incorporation. The reasons are: firstly, the controllability is closely related to the control system design; it is, therefore, traditionally assessed and enhanced in designing a control system; secondly, the available methods for the analysis of controllability are based on the mathematical model of a process. In the other words, the analysis of controllability is performed mainly by control engineers only after a complete process structure is established Huang [8]. Nevertheless, a poorly-structured process is extremely difficult to control if intense disturbances propagate through it. This implies that sound structuring of the process is essential from the viewpoints of controllability, exergy analysis, thermal effectiveness; this gives rise to the notion of fuzzy analogical gates.

To generate effectively a process with a high degree of structural controllability, a distributed strategy is capable of dealing with synthesis problems which are either pinched or pseudo-pinched, and separable or inseparable under different degrees of disturbances and various levels of control precision. It has been successfully applied to HENs; each of resultant networks satisfies the criterion of high degree of controllability, preventing the process structure from repeated modification and drastically simplifying the design of the process control system Huang [9].

In this paper a new strategy to synthesis optimum controllable heat exchanger networks has been presented; the proposed strategy consists of four sequential steps. Two analogical gates (symmetric and asymmetric) are employed. The symmetric gate (AND gate) inputs are the index of structural controllability and thermal effectiveness. The asymmetric gate (Invoke gate) inputs are the output of the AND gate and the normalized irreversibility. The proposed method has been applied for two problems well-known in published literature. The results of these case studies show that the present strategy is both robust and accurate when the index of controllability is the same for different networks and it's too hard to decide the optimum controllable network, also is essential from the viewpoints of exergy analysis, thermal effectiveness 


\section{STRUCTURAL CONTROLLABILITY}

How well the synthesized process responds to these disturbances and how effectively its control functions determine the process dynamic characteristics, and consequently, its controllability. It is obvious that a process is completely controllable if all its streams are isolated from each other, i.e. none of the streams are interconnected; thereby no disturbance can propagate from one stream to another. Nevertheless, such a process is extremely undesirable from the standpoint of its economic efficiency. Hence, the interconnections among process streams can be avoided. This implies that the controllability of a process can be assessed by examining the disturbance propagation in a process structure. The following two statements, therefore, define the concept of structural controllability:

1. A process is completely controllable structurally if disturbance does not propagate through it.

2. A process is highly controllable structurally if undesirable propagation of intense disturbances does not occur in it.

Note that two distinct features can be discerned in the above definition of structural controllability of a process. First, no mathematical model of the process is required in applying the concept; in contrast a fairly complete and precise mathematical model must always be established first in resorting to the conventional concept of controllability Kalman [10] or structural controllability Line [11] Thus, it is possible to incorporate the structural controllability into the process in the process synthesis phase where its complete structure is unavailable. Second, in applying this concept, only the paths of disturbance propagation must be examined to determine how detrimental they are to the structural controllability.

\subsection{Classification of Process Information}

In constructing an exchange network, it is sufficient to understand only semi-quantitatively its features or characteristics in the conceptual design phase, or process synthesis phase. This can be facilitated by approximate classification of information pertaining to the network, including the types of disturbance sources, the controlled or output variables, the intensity of disturbances, the level of control precision and the patterns of disturbance propagation Huang and Fan [12]. Identification of disturbance sources and output variables; the disturbances experienced by the input and output variables of an exchanger network need to be identified at the process synthesis phase. For example, the disturbances experienced by a HEN include fluctuations in stream source temperatures and heat capacity flowrates; the output variables affected by such fluctuations are target temperatures of the process stream in a HEN.

\subsubsection{Degree of Intensity of Disturbance}

The more intense disturbances of the input variables, further the output variables deviate from their normal values or set points. Based on the magnitude of disturbances in the input variables at an inlet of the network, the degrees of intensity of disturbances can be classified into three degrees:

Degree-1: slight disturbance Degree-2: moderate disturbance

Degree-3: intense disturbance $(\bullet)$

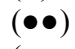

$(\bullet \bullet \bullet)$
The quantification of disturbances is determined according to the type of synthesis problem. In HEN, for a stream i, a disturbance of the source temperature $\delta T_{i}^{s}$ or that of the heat capacity flowrate $\delta M_{C p i}$ leads to a change in the heat duty $\delta Q_{i}$. Hence, $\delta Q_{i}$ is regarded as being caused by both $\delta T_{i}^{s}$ and $\delta M_{C p i}$; it is defined as follows:

$$
\delta Q_{i} \approx \max \left\{\begin{array}{l}
\left|M_{C p i} \delta T_{i}^{S(+)}-M_{C p i}{ }^{(+)}\left(T_{i}^{T}-T_{i}^{S}\right)\right|, \\
\left|M_{C p i} \delta T_{i}^{S(-)}-M_{C p i}{ }^{(-)}\left(T_{i}^{T}-T_{i}^{S}\right)\right|
\end{array}\right\}
$$

The degree of disturbance is classified according to the magnitude of $\delta Q_{i}$ which is a function of the normal values of heat capacity flowrate, source and target temperatures, and magnitudes of deviations of these quantities from the normal values in both positive and negative directions. The linguistic terms slight, moderate and intense disturbances, are defined approximately as:

$\left.\begin{array}{ll}\text { Slight disturbance } & \delta Q_{i} \leq 2 \%\left|Q_{i}\right| \\ \text { Moderate disturbance } & 2 \%\left|Q_{i}\right| \prec \delta Q_{i} \leq\left|Q_{i}\right| \\ \text { Intense disturbance } & \delta Q_{i} \succ 5 \%\left|Q_{i}\right|\end{array}\right\}$

\subsubsection{Levels of Control Precision}

Usually, it is unnecessary to control all output variables of a process to the same level of precision. For example, the temperature of a stream to a reactor need be controlled very precisely, while that to a dryer need not be; the composition of a highly toxic species in a stream need be controlled very precisely, while that of a nontoxic component in the stream need not be. Heuristically, the control precision of each output variable is divided into three levels:

Level-1: low control precision Level-2: moderate control precision Level-3: high control precision

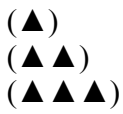

The quantification of the levels of control precision also depends upon the nature of a synthesis problem. In HEN, for instance, the control precision of output variables $T_{i}^{T}$ of stream i, can be roughly classified based on the magnitude of the deviation of target temperature $\delta T_{i}^{T}$.

$\left.\begin{array}{ll}\text { Low control precision } & \delta T_{i}^{T} \succ 5 K \\ \text { Moderate control precision } & 2 K \prec \delta T_{i}^{T} \leq 5 K \\ \text { High control precision } & \delta T_{i}^{T} \leq 2 K\end{array}\right\}$

\subsubsection{Patterns of Disturbance Propagation}

Disturbances originating from the inlets of an exchanger network propagate essentially through its downstream paths to its outlets Linnhoff and Kotjabasakis [13]. A disturbance may propagate across a pinch point in the network if an appropriate downstream path exists. The effect of any of these disturbances on an output variable of the network depends on the distance of the outlet from the inlet, or the "downstreampath length". Consequently, the disturbance propagation can be classified into four patterns according to the downstreampath lengths. The path length is determined by the number of process units involved in the path. Four patterns of disturbance propagation identified by Huang and Fan [12]

Pattern-1: very severe propagation (Through 0 or 1 process unit). 
Pattern-2: severe propagation (Through 2 process units). Pattern-3: moderate propagation (Through 3 process units). Pattern-4: negligible propagation (Through 4 or more process units)

\subsection{Index of Structural Controllability}

The degree of structural controllability of a network reaches a maximum when the occurrences and severities of undesirable disturbance propagation are at a minimum. Thus, the structural controllability can be assessed by examining the modes or patterns of disturbance propagation through the network. To evaluate the structural controllability quantitatively, it is convenient to define the disturbance vector, $D$ the control precision vector, $C$ and the disturbance propagation matrix, $P$ for a process having N streams.

\subsubsection{Disturbance Vector D}

Vector $D$ comprises all disturbances existing in a network.

Each element $d_{i}$ in vector $D$ represents a disturbance exerted at the inlet of stream $i$ of the network; this vector has the form of:

$D=\left[\begin{array}{c}d_{1} \\ d_{2} \\ \vdots \\ d_{N}\end{array}\right]$

\subsubsection{Control Precision Vector C:}

Vector $C$ specifies the levels of control precision required for all output variables. Each element $c_{j}$ in vector $C$ represents the control precision required at the outlet of stream $j$ of the network; this vector has the form of:

$$
C=\left[\begin{array}{c}
c_{1} \\
c_{2} \\
\vdots \\
c_{N}
\end{array}\right]
$$

\subsubsection{Disturbance Propagation Matrix P:}

A disturbance propagates through one or more disturbance paths and affects the stabilities of some output variables; Element $P_{i, j}$ in matrix $P$ represents a disturbance propagating from the inlet of stream $i$ to the outlet of stream $j$ in the network. The value of $P_{i, j}$ corresponds to the intensity of the propagation; this matrix has the form of:

$$
P=\left[\begin{array}{cccc}
P_{1,1} & P_{1,2} & \ldots & P_{1, N} \\
P_{2,1} & P_{2,2} & \ldots & P_{2, N} \\
\vdots & \vdots & \ddots & \vdots \\
P_{N, 1} & P_{N, 2} & \ldots & P_{N, N}
\end{array}\right]
$$

\subsubsection{Fuzzy Value Assignment:}

According to the pattern of disturbance propagation defined previously, a value can be assigned subjectively to entry $P_{i, j}$ in matrix $P$ as follows:

$$
P_{i, j}= \begin{cases}1.00, & \text { pattern }-1 \text { propagation, } \\ 0.50, & \text { pattern }-2 \text { propagation, } \\ 0.25, & \text { pattern }-3 \text { propagation, } \\ 0.00, & \text { pattern }-4 \text { propagation. }\end{cases}
$$

Note that assigning a value to $P_{i, j}$ correspond to the establishment of a "fuzzy" relation between disturbance sources $\mathrm{i}$ and controlled variable $\mathrm{j}$. The larger value is the more intense in disturbance propagation. In addition to assigning a value to each element $P_{i, j}$ in matrix $P$, a value to each element $d_{i}$ in vector $D$ and that to each element $c_{j}$ in vector $C$ can be also fuzzily assigned as follows:

$$
d_{i}=\left\{\begin{array}{ccc}
0, & \text { Degree }-1 & \text { disturbance, } \\
0.5, & \text { Degree }-2 & \text { disturbance, } \\
1, & \text { Degree }-3 & \text { disturbance }
\end{array}\right.
$$

And

$$
c_{j}= \begin{cases}0, & \text { Level }-1 \text { precision, } \\ 0.5, & \text { Level }-2 \text { precision, } \\ 1, & \text { Level }-3 \text { precision. }\end{cases}
$$

\subsubsection{Quantification of Index of Structural Controllability}

The index of structural controllability is generated by combining vectors $D$ and $C$, and matrix $P$. The stability of dynamic response of output variable $y_{i}$ is determined by the following vectors:

1. The intensity of disturbances expressed by the values of elements $d_{i, s}(i=1,2, \ldots N)$, in vector $D$.

2. The patterns of disturbance propagation reflected by the values of elements in column $j$ of matrix $P$.

3. The level of control precision of output variable $y_{i}$, i.e. $c_{j}$ in vector $C$.

The effects of all the patterns of disturbance propagation involved on the controllability of $y_{i}$ namely $E_{j}$ can be expressed as follows:

$$
\begin{aligned}
E_{j} & =\left[\begin{array}{llll}
d_{1} & d_{1} & \ldots & d_{N}
\end{array}\right]\left[\begin{array}{c}
P_{1, j} \\
P_{2, j} \\
\vdots \\
P_{N, j}
\end{array}\right] c_{j} \\
& =\left(\sum_{i=1}^{N} d_{i} P_{i, j}\right) c_{j}
\end{aligned}
$$

Obviously, the overall effect on all the output variables $y_{i, s}$, i.e. $E_{t o t}$, can be calculated as:

$$
E_{\text {tot }}=\sum_{j=1}^{N} E_{j}
$$

This equation can be written in the following form:

$$
E_{\text {tot }}=D^{T} P C
$$




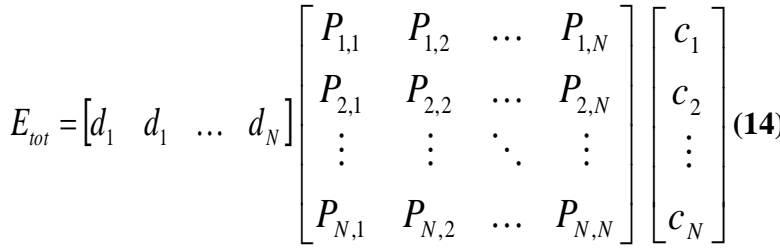

$E_{t o t}=\sum_{i=1}^{N} \sum_{j=1}^{N} d_{i} P_{i} C_{j}$

According to the definition of matrix $P$, each diagonal element $P_{i, j}$ represents the disturbance propagation from the inlet of stream $i$ to its outlet; such an element must have a value of 1 ; however, any nondiagonal element $P_{i, j}(i \neq j)$ can be $0.00,0.25,0.5$ or 1.00 . When all these nondiagonal elements have a value of 0 , the matrix $P$ is reduced to unit matrix $I$. Thus:

$$
\begin{aligned}
& \left.E_{\text {tot }, o p t}=D^{T} P_{o p t} C\right]_{P=1}=D^{T} I C \\
& =\left[\begin{array}{llll}
d_{1} & d_{1} & \ldots & d_{N}
\end{array}\right]\left[\begin{array}{cccc}
1 & 0 & \ldots & 0 \\
0 & 1 & \ldots & 0 \\
\vdots & \vdots & \ddots & \vdots \\
0 & 0 & \ldots & 1
\end{array}\right]\left[\begin{array}{c}
c_{1} \\
c_{2} \\
\vdots \\
c_{N}
\end{array}\right] \\
& =\left[\begin{array}{llll}
d_{1} & d_{1} & \ldots & d_{N}
\end{array}\right]\left[\begin{array}{c}
c_{1} \\
c_{2} \\
\vdots \\
c_{N}
\end{array}\right] \\
& =D^{T} C=\sum_{i=1}^{N} d_{i} C_{j}
\end{aligned}
$$

Now the index of structural controllability, $I_{S C}$ can be defined based on $E_{\text {tot }}$ and $E_{\text {tot,opt }}$ as

$$
I_{S C}=\left(\frac{E_{t o t, o p t}}{E_{t o t}}\right)
$$

Or

$$
I_{S C}=\left(\frac{D^{T} C}{D^{T} P C}\right)
$$

\subsubsection{Controllability Assessment Table}

This table is created based on the measure of structural controllability discussed in the preceding section Huang [12]. In the table, the first column contains all disturbance sources exerted on the input variables, the first row contains the output variables, the second column, vector $\mathrm{D}$, and the second row, vector $\mathrm{C}$, list the degrees of intensity of the disturbances and the levels of control precision, respectively. For a network synthesis problem containing $\mathrm{N}$ input variables and $\mathrm{N}$ output variables, the dimension of the table, or matrix $\mathrm{P}$, is $\mathrm{N} \times \mathrm{N}$. Each entry in the matrix indicates the disturbance propagation from a disturbance source in the corresponding row to an output variable in the corresponding column. In synthesizing a specific network, the value of each element in both vectors $\mathrm{D}$ and $\mathrm{C}$ is estimated according to the procedure given in the preceding section. The value of each element in matrix $\mathrm{P}$ is assigned based on the assessment of paths of disturbance propagating through the process structure. The structure will remain incomplete until the termination of the structure evolution stage. The table reveals all existing disturbance paths and the intensity of disturbance propagation.

\section{THERMAL EFFECTIVENESS}

This method of analysis was first published in the 1930s. Its use was restricted due to the large computational calculations required to generate design charts for a comprehensive range of heat exchanger types and configurations. The thermal effectiveness of a heat exchanger $\boldsymbol{E}$ is defined as the amount of heat actually transferred divided by the maximum amount of theoretically transferable heat.

$\varepsilon=\left(\frac{Q}{Q_{\max }}\right)$

Comprehensive equations, design charts and detailed design and performance usage have been developed for the estimation of the heat exchanger effectiveness ESDU [14], Kays and London, [15]. The thermal effectiveness is a dimensionless parameter and is a function of six variables:

$\varepsilon=$ Function (NTU, $\mathrm{C}^{*}$, Configuration, flow, arrangement stream types mixed or unmixed).

The number of heat transfer units, NTU, is a dimensionless parameter that is a combination of the physical size of the heat exchanger, the overall heat transfer coefficient and the smaller, either $\mathrm{C}_{h}$ or $\mathrm{C}_{c}$, of the two thermal capacity rates. Also, the NTU can be expressed as the heat exchanging capacity between the two streams involved in the heat exchanger.

$$
N T U=\left[\frac{U A}{C_{\min }}\right]
$$

The thermal capacity of a stream $C^{*}$ is the product of the mass flow rate and the average specific heat capacity. In a two stream heat exchanger, the thermal capacity ratio, $\mathrm{C}_{\mathrm{s}}$, is the ratio of the smaller thermal capacity to the larger. Hence, the values for $C^{*}$ go from 0 to 1 .

$$
C^{*}=\left(\frac{C_{\min }}{C_{\max }}\right)=\frac{\left(m^{\bullet} C p\right)_{\min }}{\left(m^{\bullet} C p\right)_{\max }}
$$

Using the inlet and outlet temperature of a heat exchanger, the definition of thermal effectiveness can be rewritten as follows:

$$
\varepsilon=\frac{C_{h}\left(T_{h 1}-T_{h 2}\right)}{C_{\min }\left(T_{h 1}-T_{c 1}\right)}=\frac{C_{c}\left(T_{c 2}-T_{c 1}\right)}{C_{\min }\left(T_{h 1}-T_{c 1}\right)}
$$

When dealing with disturbances, the value of the thermal effectiveness will be affected only when mass-flow rate disturbance occur. Temperature disturbances do not alter the value of $\mathcal{E}$. For example, a variation in the mass-flow rate of either the hot or cold stream, will lead to a change in the value of the following parameters: the individual and overall heat transfer coefficient, NTU and the value of $\mathrm{C}^{*}$. Finally, all these variations will cause an effect in the heat transfer duty and the values of the both outlet temperatures, $T_{h 2}$ and $T_{c 2}$, Picon and Polley [16] 
The value of the thermal effectiveness is determined from the appropriate chart or equation once the particular heat exchanger configuration, flow arrangement and geometry has been provided Abu Khader [17]. The determination of changes in the performance of a heat exchanger due to disturbances is easy to manage by using this methodology. A computer simulator is easy to build because mathematical expressions for a great number of configurations and flow arrangements are already available in the open literature. The $\varepsilon$-NTU method is easy and straight forward. It can be implemented to determine the changes in heat exchanger performance without a trial and error procedure Fidel [18].

\section{EXERGY ANALYSIS}

Exergy is a term used to define the available energy that could be extracted from a thermodynamic system. This term is required because of irreversibility of all real process. Exergy is used to describe the quality of energy rather its quantity as enthalpy. Exergy of a system is defined as the theoretical maximum amount of work that could be obtained from a system at a prescribed state when operating with a reservoir at the constant pressure and temperature, $\mathrm{P}_{\mathrm{o}}$ and $\mathrm{T}_{\mathrm{o}}$. The specific exergy of any system is:

$$
\Delta E x=\Delta H-T_{0} \Delta S
$$

Exergy efficiencies can be used in many applications such as analyzing and optimizing processes and systems. Exergy analysis usually includes a detailed calculation of the exergy values of process flow and the exergy losses in the system; also it identifies the place in the system where losses occur and the extent of these losses, and shows how this loss can be limited.

Exergy efficiency, which is the exergy loss compared with the added or transferred exergy, gives a better picture of the quality of the process than the absolute exergy loss. Also it can be used to check if the process calculation is true or not by comparing the calculated exergy efficiency for the process with the usual efficiency for these apparatuses Predrag [19]. The universal efficiency is based on a generally workable definition for exergy efficiency. It is rejected as insufficient in the publications stated. The functional efficiency is preferred, but requires further specification, depending on the type of system.

The universal efficiency can be defined as follows

$$
\eta_{u}=\frac{\sum E x_{\text {in }}-\sum E x_{\text {loss }}}{\sum E x_{i n}}=1-\frac{\sum E x_{\text {loss }}}{\sum E x_{i n}}
$$

The universal efficiency offers a clear definition for a variety of systems. A disadvantage of this definition, however, is that the efficiency values obtained can be insensitive to changes in the system. This occurs, for example, when only part of the flows undergo a change or when the flows undergo only minor changes. The exergy loss is then small compared to the exergy of the ingoing energy flows. In that the exergy flows contain large "ballast flows": exergy flows that are actually fed to the process, but not directly involved in the intended conversion. As a result of these ballast flows, the universal efficiency may be insensitive to changes in exergy loss.

This is the reason for defining functional efficiency. In the functional efficiency the influence of ballast flows is eliminated as much as possible in order to achieve the highest possible sensitivities to changes in the system. Other names, however, are used for functional efficiency: rational efficiency, efficiency with transiting exergy, etc...
The functional efficiency can be defined as:

$\eta_{f}=\frac{\sum E x_{\text {Source }}-\sum E x_{\text {loss }}}{\sum E x_{\text {Source }}}=1-\frac{\sum E x_{\text {loss }}}{\sum E x_{\text {Source }}}$

Exergy Supplied by Hot \& cold Stream can be calculated by the following equation

$$
\Delta E x_{H o t}=\Delta H\left(1-\frac{T_{0}}{T_{A M}}\right)
$$

Also the Irreversibility,

$$
\text { Irreversibility } \left.=\Delta E x]_{H o t}-\Delta E x\right]_{\text {Cold }}
$$

\section{FUZZY ANALOGICAL GATES STRATEGY}

The algorithm followed in this step is selecting the best weight index and it consists of three sequential steps:

i. Estimation of the index of structural controllability, the thermal effectiveness of networks and normalized irreversibility.

ii. Fuzzy analogical gates network.

iii. Selection of the best weight index.

\subsection{Fuzzy Analogical Gates Network}

Two fuzzy analogical gates will be used sequentially as shown in Fig.1. The first gate is selected to be symmetric and the second gate is asymmetric. A fuzzy analogical - AND gate will be followed by a fuzzy invoke gate Hussein [20]

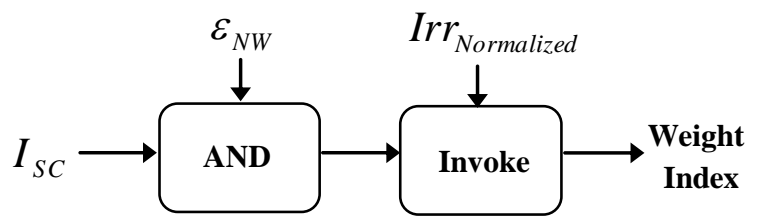

Fig.1. Fuzzy analogical gates network.

The symmetric gate inputs are the index of structural controllability $\left(I_{S C}\right)$ and the thermal effectiveness of network $\left(\varepsilon_{N W}\right)$. The asymmetric gate inputs are the output of the symmetric gate and $I r r_{\text {Normalized }}$.

\subsection{Choice of the Best Weight Index}

The final step corresponds to the choice of the best weight Index. The operation is carried out by comparing (W.I) values for all solution of network configuration and by choosing the greatest one.

W.I ${ }_{\text {optimum }}=\max \left\{\mathrm{W} . \mathrm{I}_{1}, \mathrm{~W} . \mathrm{I}_{2}, \mathrm{~W} . \mathrm{I}_{3} \ldots \ldots\right\}$

\section{PROBLEM STATEMENT}

The HEN synthesis problem to be addressed in this paper can be stated as follows: A set of hot streams to be cooled and cold streams to be heated are given; which include stream data and by imposing hypothetical disturbances on the stream source temperatures and heat capacity flow rates. The basic objective of the HENS problem is to synthesize a network of heat exchangers, which facilitate the desired heat exchange, while keeping fluctuations under control. When the network is 
already designed some corrective actions must be taken in order to preserve the controllability of the process, such as index of structural controllability, thermal effectiveness and exergy analysis. Fuzzy analogical gates strategy is employed in the present work to select the optimum controllable heat exchanger networks.

\section{EXAMPLES}

The proposed strategy will be tested using two case studies reported in the literature, for comparison.

\subsection{Example 1}

The popular Aromatics plant problem is the subject for this case study. It is generated from the commonly Aromatics problem, [21] by imposing hypothetical disturbances on the stream source temperatures and heat capacity flowrates; the specifications for all streams data are shown in Table.1. Degree of intensity of disturbance, levels of control precision are shown in Table 2 and 3. The pinch point is located at the temperature of $111.25^{\circ} \mathrm{C}$ according to the normal values of the source and target temperatures and heat capacity flow rates of all streams. Consequently, the minimum number of HTU's under minimum energy requirements (MER), is equal to 14 including heater and coolers. The MER is $23080 \mathrm{~kW}$. The grid diagrams for solutions are shown in Fig. 2, 3, 4 and 5.

\subsection{Example 2 (H5SP1R)}

A HEN synthesis problem, named H5SP1R, contains five process streams. It is generated from the commonly used test problem, problem 5SP1, [9] by imposing hypothetical disturbances on the stream source temperatures and heat capacity flowrates; the specifications for all streams data are shown in Table 20. Degree of intensity of disturbance, levels of control precision are shown in Table 21 and 22. In this pseudo-pinched problem, the pinch point is located at the temperature of $43.5^{\circ} \mathrm{C}$ according to the normal values of the source and target temperatures and heat capacity flow rates of all streams. Consequently, the minimum number of HTU's under minimum energy requirements (MER), is equal to 5 including a heater. The MER is $884.6 \mathrm{~kW}$. The grid diagrams for solutions are shown in Fig.6, 7, 8, 9 and 10.

Table.1. Stream Data of Aromatics HEN synthesis problem.

\begin{tabular}{|c|c|c|c|c|c|c|c|c|c|}
\hline Stream & $\mathbf{T}_{\mathbf{i}} \mathbf{S}\left({ }^{\circ} \mathbf{C}\right)$ & $\mathbf{T}_{\mathbf{i}}{ }^{\mathrm{t}}\left({ }^{\circ} \mathbf{C}\right)$ & $\begin{array}{c}\mathbf{M}_{\mathrm{Cpi}} \\
\left(\mathbf{k W} /{ }^{\circ} \mathrm{C}\right)\end{array}$ & $\begin{array}{c}\delta \mathbf{T}_{\mathbf{i}}^{\mathbf{S ( + )}} \\
\left({ }^{\circ} \mathbf{C}\right)\end{array}$ & $\begin{array}{c}\delta \mathbf{T}_{\mathbf{i}}^{\mathbf{S}(-)} \\
\left({ }^{\circ} \mathbf{C}\right) \\
\end{array}$ & $\begin{array}{c}\mathbf{S M}_{\mathrm{Cpp}}{ }^{(+)} \\
\left(\mathbf{k W} /{ }^{\circ} \mathbf{C}\right)\end{array}$ & $\begin{array}{c}\boldsymbol{\delta} \mathbf{M}_{\mathbf{C p p}}{ }^{(-)} \\
\left(\mathbf{k W} /{ }^{\circ} \mathbf{C}\right)\end{array}$ & $\begin{array}{l}\delta \mathbf{T}_{\mathbf{i}}^{\mathbf{t}} \\
\left({ }^{\circ} \mathbf{C}\right)\end{array}$ & $\begin{array}{c}\mathbf{Q}_{\mathbf{i}} \\
(\mathbf{k W})\end{array}$ \\
\hline H1 & 327 & 40 & 100 & 2.0 & 2.0 & 0.36 & 0.42 & 5.64 & 28700 \\
\hline $\mathrm{H} 2$ & 220 & 160 & 160 & 1.0 & 1.6 & 0.12 & 0.2 & 6.5 & 9600 \\
\hline $\mathrm{H} 3$ & 220 & 60 & 60 & 1.0 & 0.8 & 0.08 & 0.1 & 5.5 & 9600 \\
\hline $\mathrm{H} 4$ & 160 & 45 & 400 & 0.44 & 0.8 & 0.3 & 0.4 & 1.8 & 46000 \\
\hline $\mathrm{C} 1$ & 100 & 300 & 100 & 2.6 & 2.0 & 1.0 & 0.8 & 3.6 & 20000 \\
\hline $\mathrm{C} 2$ & 35 & 164 & 70 & 3.7 & 4.1 & 1.4 & 1.0 & 2.2 & 9030 \\
\hline $\mathrm{C} 3$ & 85 & 138 & 350 & 1.82 & 0.8 & 0.4 & 0.4 & 4.0 & 18550 \\
\hline $\mathrm{C} 4$ & 60 & 170 & 60 & 2.8 & 1.6 & 0.06 & 0.2 & 6.0 & 6600 \\
\hline $\mathrm{C} 5$ & 140 & 300 & 200 & 4.2 & 2.4 & 0.04 & 0.14 & 5.5 & 32000 \\
\hline
\end{tabular}

Table.2. Quantification of disturbance information

\begin{tabular}{ccc}
\hline Stream & $\boldsymbol{\delta} \boldsymbol{Q i}(\boldsymbol{k W})$ & Degree of intensity of disturbance \\
\hline $\mathbf{H 1}$ & 96.68 & Slight disturbance \\
$\mathbf{H} 2$ & 244 & Moderate disturbance \\
$\mathbf{H 3}$ & 47.2 & Slight disturbance \\
$\mathbf{H 4}$ & 274 & Slight disturbance \\
$\mathbf{C 1}$ & 60 & Slight disturbance \\
$\mathbf{C 2}$ & 158 & Slight disturbance \\
$\mathbf{C 3}$ & 615.8 & Moderate disturbance \\
$\mathbf{C 4}$ & 161.4 & Moderate disturbance \\
$\mathbf{C 5}$ & 833.6 & Moderate disturbance \\
\hline
\end{tabular}

The intensity of a disturbance caused by the fluctuations of temperature and / or heat capacity flowrate is indicated by the number of solid circles $(\bullet)$. The greater number of solid circles, the greater the intensity. The table indicates that hot streams H1, H3and $\mathrm{H} 4$; cold streams $\mathrm{C} 1$ and $\mathrm{C} 2$ experienceDegree - 1 disturbance, i.e. slight disturbance at their inlets; the remaining streams experienceDegree2 disturbance, i.e. moderate disturbance

The precision of control at a stream outlet is indicated by the number of triangles $(\boldsymbol{\Delta})$; the greater number of triangles, the higher the level of control precision..The outlet of hot stream $\mathrm{H} 4$ must be controlled withLevel -3 precision, i.e. high control precision; the outlet of cold streams $\mathrm{C} 1, \mathrm{C} 2$ and $\mathrm{C} 3$
Table.3. Quantification of level control precision information

\begin{tabular}{ccc}
\hline Stream & $\boldsymbol{\delta} \boldsymbol{T}_{\boldsymbol{i}}^{\boldsymbol{t}}\left({ }^{\circ} \boldsymbol{K}\right)$ & Level of control precision \\
\hline $\mathbf{H 1}$ & 5.64 & Low control precision \\
$\mathbf{H 2}$ & 6.5 & Low control precision \\
$\mathbf{H 3}$ & 5.5 & Low control precision \\
$\mathbf{H 4}$ & 1.8 & High control precision \\
$\mathbf{C 1}$ & 3.6 & Moderate control precision \\
$\mathbf{C 2}$ & 2.2 & Moderate control precision \\
$\mathbf{C 3}$ & 4.0 & Moderate control precision \\
$\mathbf{C 4}$ & 6.0 & Low control precision \\
$\mathbf{C 5}$ & 5.5 & Low control precision \\
\hline
\end{tabular}

with Level -2 precision, i.e. moderate control precision; and each of the outlets of the remaining streams withLevel 1 precision, i.e. low control precision.

The following Tables 4, 5, 6, and 7 represent disturbance propagation of different solutions of networks. An integer of [1] and [0] reflects the existence of pattern-1 propagation of disturbance, an integer of [2] reflects the existence of pattern-2 propagation of disturbance, an integer of [3] reflects the existence of pattern-3 propagation of disturbance. An integer of [4] reflects the existence of pattern- 4 propagation of disturbance. 
Table.4. Disturbance propagation (Solution A)

\begin{tabular}{|c|c|c|c|c|c|c|c|c|c|c|}
\hline \multirow[t]{2}{*}{$\stackrel{\check{\Xi}}{\Xi}$} & $\frac{\widetilde{\Xi}}{\mathbb{\Xi}}$ & $\Xi$ & בี & $\ddot{\Xi}$ & $\mathbb{I}$ & $\bar{U}$ & Ư & $\tilde{U}$ & む & 10 \\
\hline & \multicolumn{10}{|c|}{$D P$} \\
\hline \multicolumn{2}{|c|}{ H1 } & 1 & 4 & 0 & 3 & 1 & 2 & 3 & 0 & 2 \\
\hline \multicolumn{2}{|c|}{ H2 } & 0 & 1 & 3 & 0 & 0 & 2 & 1 & 3 & 2 \\
\hline \multicolumn{2}{|c|}{ H3 } & 3 & 0 & 1 & 0 & 3 & 0 & 0 & 0 & 2 \\
\hline \multicolumn{2}{|c|}{ H4 } & 0 & 2 & 0 & 1 & 0 & 2 & 1 & 0 & 0 \\
\hline \multicolumn{2}{|c|}{ C1 } & 2 & 0 & 0 & 4 & 1 & 3 & 4 & 0 & 0 \\
\hline \multicolumn{2}{|c|}{$\mathrm{C2}$} & 2 & 1 & 0 & 2 & 0 & 1 & 2 & 0 & 0 \\
\hline \multicolumn{2}{|c|}{ C3 } & 0 & 1 & 0 & 2 & 0 & 0 & 1 & 0 & 0 \\
\hline \multicolumn{2}{|c|}{ C4 } & 0 & 0 & 2 & 0 & 0 & 0 & 0 & 1 & 0 \\
\hline \multicolumn{2}{|c|}{ C5 } & 2 & 1 & 2 & 0 & 2 & 2 & 0 & 2 & 1 \\
\hline
\end{tabular}

All patterns of disturbance propagation involved are listed in the disturbance propagation table. The first column of the table designates the inlets of nine streams; the first row designates their outlets. Each integer in the remaining entries of the table represents the pattern of disturbance propagation. For example an integer of 1 in entry $(\mathrm{H} 1, \mathrm{C} 1)$ reflects the existence of pattern-1 propagation of disturbance originating from the inlet of hot stream $\mathrm{H} 1$, passing through exchanger 8, and reaching the outlet of cold stream $\mathrm{C} 1$. A disturbance exerted at the inlet of hot stream $\mathrm{H} 2$ propagates through exchangers $3 \& 4$, and reaches the outlet of cold stream $\mathrm{C} 2$. This is pattern-2 propagation, and thus an integer of 2 is assigned to entry ( $\mathrm{H} 2$ \& $\mathrm{C} 2$ ). Between the inlet of hot stream H3 \& the outlet of cold stream $\mathrm{C} 1$, we can find pattern-3 disturbance propagation in which exchangers 10, $6 \& 9$ are involved sequentially, and thus an integer of 3 appears in entry (H1, C3). Pattern 4 disturbance propagation exists from the inlet of hot stream $\mathrm{H} 1$, passes through exchangers $(10,6,9$ and 5) and arrives at the outlet of hot stream $\mathrm{H} 2$; thus entry $(\mathrm{H} 1, \mathrm{H} 2)$ has an integer of 4 . Note that Table 4 involves altogether 15 occurrences of Pattern-1 propagation, 18 occurrences of Pattern- 2 propagation, 7 occurrences of Pattern-3 propagation and 3 occurrences of Pattern-4 propagation.

Table.5. Disturbance propagation (Solution B)

\begin{tabular}{|c|c|c|c|c|c|c|c|c|c|c|}
\hline \multirow[t]{2}{*}{$\stackrel{\Xi}{\Xi}$} & 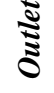 & $\Xi$ & 고 & $\mathscr{I}$ & \pm & $\bar{U}$ & U & $\tilde{3}$ & む & in \\
\hline & \multicolumn{10}{|c|}{$D P$} \\
\hline \multicolumn{2}{|c|}{ H1 } & 1 & 0 & 0 & 0 & 1 & 0 & 0 & 1 & 0 \\
\hline \multicolumn{2}{|c|}{ H2 } & 0 & 1 & 0 & 3 & 0 & 2 & 0 & 0 & 2 \\
\hline \multicolumn{2}{|c|}{ H3 } & 3 & 0 & 1 & 3 & 3 & 2 & 1 & 1 & 0 \\
\hline \multicolumn{2}{|c|}{ H4 } & 0 & 2 & 3 & 1 & 0 & 2 & 1 & 0 & 2 \\
\hline \multicolumn{2}{|c|}{ C1 } & 2 & 0 & 0 & 0 & 1 & 0 & 0 & 0 & 0 \\
\hline \multicolumn{2}{|c|}{$\mathrm{C2}$} & 0 & 1 & 2 & 2 & 0 & 1 & 2 & 0 & 3 \\
\hline \multicolumn{2}{|c|}{ C3 } & 4 & 0 & 2 & 2 & 0 & 3 & 1 & 2 & 0 \\
\hline \multicolumn{2}{|c|}{ C4 } & 2 & 0 & 2 & 0 & 2 & 0 & 0 & 1 & 0 \\
\hline \multicolumn{2}{|c|}{ C5 } & 0 & 1 & 0 & 2 & 0 & 3 & 0 & 0 & 1 \\
\hline
\end{tabular}

Table.6. Disturbance propagation (Solution C)

\begin{tabular}{|c|c|c|c|c|c|c|c|c|c|c|}
\hline \multirow{2}{*}{ 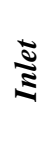 } & 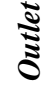 & $\bar{\Xi}$ & $\tilde{\Xi}$ & 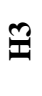 & $\mathbb{I}$ & $\bar{U}$ & $\tilde{U}$ & $\theta$ & ઇ & ' \\
\hline & \multicolumn{10}{|c|}{$D P$} \\
\hline \multicolumn{2}{|c|}{ H1 } & 1 & 0 & 0 & 0 & 0 & 2 & 1 & 0 & 0 \\
\hline \multicolumn{2}{|c|}{ H2 } & 0 & 1 & 0 & 3 & 3 & 0 & 0 & 1 & 2 \\
\hline \multicolumn{2}{|c|}{ H3 } & 3 & 2 & 1 & 0 & 1 & 2 & 0 & 0 & 2 \\
\hline \multicolumn{2}{|c|}{ H4 } & 0 & 0 & 3 & 1 & 1 & 4 & 0 & 0 & 2 \\
\hline \multicolumn{2}{|c|}{$\mathrm{C} 1$} & 0 & 0 & 2 & 2 & 1 & 3 & 0 & 0 & 0 \\
\hline \multicolumn{2}{|c|}{ C2 } & 2 & 0 & 2 & 0 & 0 & 1 & 0 & 0 & 3 \\
\hline \multicolumn{2}{|c|}{ C3 } & 2 & 0 & 0 & 0 & 0 & 3 & 1 & 0 & 0 \\
\hline \multicolumn{2}{|c|}{$\mathrm{C4}$} & 0 & 1 & 0 & 4 & 0 & 0 & 0 & 1 & 3 \\
\hline \multicolumn{2}{|c|}{ C5 } & 0 & 1 & 2 & 2 & 2 & 0 & 0 & 0 & 1 \\
\hline
\end{tabular}

Table.7. Disturbance propagation (Solution D)

\begin{tabular}{|c|c|c|c|c|c|c|c|c|c|c|}
\hline \multirow{2}{*}{$\stackrel{\Xi}{\Xi}$} & $\stackrel{\widetilde{\Xi}}{\mathbb{\Xi}}$ & $\Xi$ & $\underline{\Xi}$ & 9 & \pm & $\bar{U}$ & ป & U & பే & 8 \\
\hline & \multicolumn{10}{|c|}{$D P$} \\
\hline \multicolumn{2}{|c|}{ H1 } & 1 & 2 & 0 & 0 & 1 & 0 & 1 & 0 & 2 \\
\hline \multicolumn{2}{|c|}{ H2 } & 0 & 1 & 0 & 0 & 1 & 0 & 0 & 0 & 0 \\
\hline \multicolumn{2}{|c|}{ H3 } & 3 & 0 & 1 & 3 & 1 & 2 & 0 & 0 & 0 \\
\hline \multicolumn{2}{|c|}{ H4 } & 3 & 0 & 3 & 1 & 1 & 2 & 1 & 1 & 0 \\
\hline \multicolumn{2}{|c|}{ C1 } & 2 & 1 & 2 & 2 & 1 & 3 & 0 & 2 & 0 \\
\hline \multicolumn{2}{|c|}{$\mathrm{C} 2$} & 4 & 0 & 2 & 2 & 0 & 1 & 2 & 0 & 0 \\
\hline \multicolumn{2}{|c|}{ C3 } & 2 & 0 & 0 & 2 & 2 & 0 & 1 & 0 & 3 \\
\hline \multicolumn{2}{|c|}{$\mathrm{C4}$} & 0 & 0 & 0 & 2 & 0 & 0 & 0 & 1 & 0 \\
\hline \multicolumn{2}{|c|}{ C5 } & 2 & 0 & 0 & 0 & 2 & 0 & 0 & 0 & 1 \\
\hline
\end{tabular}

In Tables 8, 9, 10 and 11, controllability assessment with preassigned values is shown, where "1" elements in the entries (H1, H1), (H2, H2), (H3, H3), (H4, H4), (C1, C1), (C2, C2), $(\mathrm{C} 3, \mathrm{C} 3),(\mathrm{C} 4, \mathrm{C} 4)$ and $(\mathrm{C} 5, \mathrm{C} 5)$ represent the unavoidable disturbance propagation from their inlets to their outlets. Another seven "1" elements suggest the direct matches between those pairs. The " 0.5 " elements; extends through two process units along a downstream path before reaching the outlet of a stream. This pattern of propagation involves two matches. The entries contain " 0.25 " elements; this indicates that the matching between streams and gives rise to the disturbance propagation whose severity should be below the tolerable limit. Each entry with " 0 " elements signifies the immaterial match pattern between a pair of corresponding streams. Index of structural controllability for different solutions is shown in Table 12, solution $\mathrm{C}$ is the optimum one which gives high value of $\mathrm{I}_{\mathrm{SC}}$. Tables $13,14,15,16$ and 17 show the exergy analysis and normalized irreversibility results. The thermal effectiveness results for solutions A, B, C and $\mathrm{D}$ is shown in Table 18. 
Table.8. Controllability assessment (Solution A)

\begin{tabular}{|c|c|c|c|c|c|c|c|c|c|c|c|}
\hline & & $T_{i}^{t}$ & $T_{i}^{t}, H 1$ & $T_{i}^{t}, H 2$ & $T_{i}^{t}, H 3$ & $T_{i}^{t}, H 4$ & $T_{i}^{t}, C 1$ & $T_{i}^{t}, C 2$ & $T_{i}^{t}, C 3$ & $T_{i}^{t}, C 4$ & $T_{i}^{t}, C 5$ \\
\hline \multirow{2}{*}{$d Q_{i}$} & \multirow{2}{*}{$d_{i}$} & $C_{i}$ & 0 & 0 & 0 & 1 & 0.5 & 0.5 & 0.5 & 0 & 0 \\
\hline & & \multicolumn{10}{|l|}{$\boldsymbol{P}_{i i}$} \\
\hline$d Q_{i}, H 1$ & 0 & & 1 & 0 & 1 & 0.25 & 1 & 0.5 & 0.25 & 1 & 0.5 \\
\hline$d Q_{i}, H 2$ & 0.5 & & 1 & 1 & 0.25 & 1 & 1 & 0.5 & 1 & 0.25 & 0.5 \\
\hline$d Q_{i}, H 3$ & 0 & & 0.25 & 1 & 1 & 1 & 0.25 & 1 & 1 & 1 & 0.5 \\
\hline$d Q_{i}, H 4$ & 0 & & 1 & 0.5 & 1 & 1 & 1 & 0.5 & 1 & 1 & 1 \\
\hline$d Q_{i}, C 1$ & 0 & & 0.5 & 1 & 1 & 0 & 1 & 0.25 & 0 & 1 & 1 \\
\hline$d Q_{i}, C 2$ & 0 & & 0.5 & 1 & 1 & 0.5 & 1 & 1 & 0.5 & 1 & 1 \\
\hline$d Q_{i}, C 3$ & 0.5 & & 1 & 1 & 1 & 0.5 & 1 & 1 & 1 & 1 & 1 \\
\hline$d Q_{i}, C 4$ & 0.5 & & 0.5 & 1 & 1 & 0.5 & 1 & 1 & 1 & 1 & 1 \\
\hline \multirow[t]{3}{*}{$d Q_{i}, C 5$} & 0.5 & & 0.5 & 1 & 0.5 & 1 & 0.5 & 0.5 & 1 & 0.5 & 1 \\
\hline & \multicolumn{11}{|c|}{ Table.9. Controllability assessment (Solution B) } \\
\hline & \multirow{3}{*}{$d_{i}$} & $T_{i}^{t}$ & $T_{i}^{t}, H 1$ & $T_{i}^{t}, H 2$ & $T_{i}^{t}, H 3$ & $T_{i}^{t}, \mathrm{H4}$ & $T_{i}^{t}, C 1$ & $T_{i}^{t}, C 2$ & $T_{i}^{t}, C 3$ & $T_{i}^{t}, C 4$ & $T_{i}^{t}, C 5$ \\
\hline \multirow{2}{*}{$d Q_{i}$} & & $C_{i}$ & 0 & 0 & 0 & 1 & 0.5 & 0.5 & 0.5 & 0 & 0 \\
\hline & & \multicolumn{10}{|c|}{$\boldsymbol{P}_{i j}$} \\
\hline$d Q_{i}, H 1$ & 0 & & 1 & 1 & 1 & 1 & 1 & 1 & 1 & 1 & 1 \\
\hline$d Q_{i}, H 2$ & 0.5 & & 1 & 1 & 1 & 0.25 & 1 & 0.5 & 1 & 1 & 0.5 \\
\hline$d Q_{i}, H 3$ & 0 & & 0.25 & 1 & 1 & 0.25 & 0.25 & 0.5 & 1 & 1 & 1 \\
\hline$d Q_{i}, H 4$ & 0 & & 1 & 0.5 & 0.25 & 1 & 1 & 0.5 & 1 & 1 & 0.5 \\
\hline$d Q_{i}, C 1$ & 0 & & 0.5 & 1 & 1 & 1 & 1 & 1 & 1 & 1 & 1 \\
\hline$d Q_{i}, C 2$ & 0 & & 1 & 1 & 0.5 & 0.5 & 1 & 1 & 0.5 & 1 & 0.25 \\
\hline$d Q_{i}, C 3$ & 0.5 & & 0 & 1 & 0.5 & 0.5 & 1 & 0.25 & 1 & 0.5 & 1 \\
\hline$d Q_{i}, C 4$ & 0.5 & & 0.5 & 1 & 0.5 & 1 & 0.5 & 1 & 1 & 1 & 1 \\
\hline$d Q_{i}, C 5$ & 0.5 & & 1 & 1 & 1 & 0.5 & 1 & 0.25 & 1 & 1 & 1 \\
\hline
\end{tabular}

Table.10. Controllability assessment (Solution C)

\begin{tabular}{|c|c|c|c|c|c|c|c|c|c|c|c|}
\hline & & $T_{i}^{t}$ & $\mathrm{~T}_{\mathrm{i}}^{\mathrm{t}}, \mathrm{HI}$ & $\mathrm{T}_{\mathrm{i}}^{\mathrm{t}}, \boldsymbol{H} 2$ & $\mathrm{~T}_{\mathrm{i}}^{\mathrm{t}}, \mathrm{H3}$ & $\mathrm{T}_{\mathrm{i}}^{\mathrm{t}}, \mathrm{H4}$ & $\mathrm{T}_{\mathrm{i}}^{\mathrm{t}}, C 1$ & $\mathrm{~T}_{\mathrm{i}}^{\mathrm{t}}, C 2$ & $\mathrm{~T}_{\mathrm{i}}^{\mathrm{t}}, C 3$ & $\mathrm{~T}_{\mathrm{i}}^{\mathrm{t}}, C 4$ & $\mathrm{~T}_{\mathrm{i}}^{\mathrm{t}}, C 5$ \\
\hline \multirow[t]{2}{*}{$d Q_{i}$} & \multirow[t]{2}{*}{$d_{i}$} & $C_{j}$ & 0 & 0 & 0 & 1 & 0.5 & 0.5 & 0.5 & 0 & 0 \\
\hline & & \multicolumn{10}{|c|}{$\boldsymbol{P}_{i j}$} \\
\hline$d Q_{i}, H 1$ & 0 & & 1 & 1 & 1 & 1 & 1 & 0.5 & 1 & 1 & 1 \\
\hline$d Q_{i}, H 2$ & 0.5 & & 1 & 1 & 1 & 0.25 & 0.25 & 1 & 1 & 1 & 0.5 \\
\hline$d Q_{i}, H 3$ & 0 & & 0.25 & 0.5 & 1 & 1 & 1 & 0.5 & 1 & 1 & 0.5 \\
\hline$d Q_{i}, H 4$ & 0 & & 1 & 1 & 0.25 & 1 & 1 & 0 & 1 & 1 & 0.5 \\
\hline$d Q_{i}, C 1$ & 0 & & 1 & 1 & 0.5 & 0.5 & 1 & 0.25 & 1 & 1 & 1 \\
\hline$d Q_{i}, C 2$ & 0 & & 0.5 & 1 & 0.5 & 1 & 1 & 1 & 1 & 1 & 0.25 \\
\hline$d Q_{i}, C 3$ & 0.5 & & 0.5 & 1 & 1 & 1 & 1 & 0.25 & 1 & 1 & 1 \\
\hline$d Q_{i}, C 4$ & 0.5 & & 1 & 1 & 1 & 0 & 1 & 1 & 1 & 1 & 0.25 \\
\hline$d Q_{i}, C 5$ & 0.5 & & 1 & 1 & 0.5 & 0.5 & 0.5 & 1 & 1 & 1 & 1 \\
\hline
\end{tabular}

Table.11. Controllability assessment (Solution D)

\begin{tabular}{|c|c|c|c|c|c|c|c|c|c|c|c|}
\hline & & $T_{i}^{t}$ & $\mathrm{~T}_{\mathrm{i}}^{\mathrm{t}}, \mathrm{HI}$ & $\mathrm{T}_{\mathrm{i}}^{\mathrm{t}}, \mathrm{H} 2$ & $\mathrm{~T}_{\mathrm{i}}^{\mathrm{t}}, \mathrm{H3}$ & $\mathrm{T}_{\mathrm{i}}^{\mathrm{t}}, \mathrm{H4}$ & $\mathrm{T}_{\mathrm{i}}^{\mathrm{t}}, C 1$ & $\mathrm{~T}_{\mathrm{i}}^{\mathrm{t}}, C 2$ & $\mathrm{~T}_{\mathrm{i}}^{\mathrm{t}}, C 3$ & $\mathrm{~T}_{\mathrm{i}}^{\mathrm{t}}, C 4$ & $\mathrm{~T}_{\mathrm{i}}^{\mathrm{t}}, C 5$ \\
\hline \multirow[t]{2}{*}{$d Q_{i}$} & \multirow[t]{2}{*}{$d_{i}$} & $C_{j}$ & 0 & 0 & 0 & 1 & 0.5 & 0.5 & 0.5 & 0 & 0 \\
\hline & & \multicolumn{10}{|c|}{$P_{i j}$} \\
\hline$d Q_{i}, H 1$ & 0 & & 1 & 0.5 & 1 & 1 & 1 & 1 & 1 & 1 & 0.5 \\
\hline$d Q_{i}, H 2$ & 0.5 & & 1 & 1 & 1 & 1 & 1 & 1 & 1 & 1 & 1 \\
\hline$d Q_{i}, H 3$ & 0 & & 0.25 & 1 & 1 & 0.25 & 1 & 0.5 & 1 & 1 & 1 \\
\hline$d Q_{i}, H 4$ & 0 & & 0.25 & 1 & 0.25 & 1 & 1 & 0.50 & 1 & 1 & 1 \\
\hline$d Q_{i}, C 1$ & $\mathbf{0}$ & & 0.5 & 1 & 0.5 & 0.5 & 1 & 0.25 & 1 & 0.5 & 1 \\
\hline$d Q_{i}, C 2$ & 0 & & 0 & 1 & 0.5 & 0.5 & 1 & 1 & 0.5 & 1 & 1 \\
\hline$d Q_{i}, C 3$ & 0.5 & & 0.5 & 1 & 1 & 0.5 & 0.5 & 1 & 1 & 1 & 0.25 \\
\hline$d Q_{i}, C 4$ & 0.5 & & 1 & 1 & 1 & 0.5 & 1 & 1 & 1 & 1 & 1 \\
\hline$d Q_{i}, C 5$ & 0.5 & & 0.5 & 1 & 1 & 1 & 0.5 & 1 & 1 & 1 & 1 \\
\hline
\end{tabular}


Table.12. Comparison of the Solutions for Heat Exchanger Network Synthesis Problem

\begin{tabular}{|c|c|c|c|c|c|}
\hline \multirow{2}{*}{\multicolumn{2}{|c|}{ criterion }} & \multicolumn{4}{|c|}{ Solution } \\
\hline & & $\mathbf{A}$ & B & $\mathbf{C}$ & D \\
\hline \multicolumn{2}{|r|}{$\operatorname{MER}(\mathbf{k W})$} & 23080 & 23080 & 23080 & $0 \quad 23080$ \\
\hline \multicolumn{2}{|r|}{ NTU } & 14 & 14 & 13 & 14 \\
\hline \multicolumn{2}{|r|}{$\mathbf{I}_{\mathrm{SC}}\left(\boldsymbol{\mu}_{1}\right)$} & 0.286 & 0.357 & 0.370 & 0.294 \\
\hline \multicolumn{6}{|c|}{ Table.13. Exergy Analysis Results for Solution A } \\
\hline 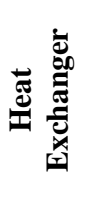 & 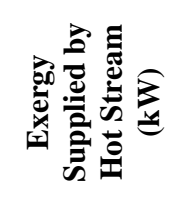 & 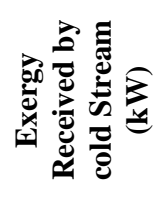 & 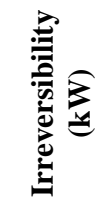 & \multicolumn{2}{|r|}{ 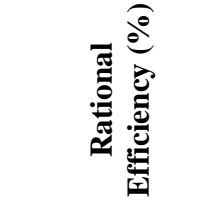 } \\
\hline 1 & 0231.680 & 0167.501 & \multicolumn{2}{|c|}{0064.179} & 72.298 \\
\hline 2 & 0651.290 & 0563.308 & \multicolumn{2}{|c|}{0087.982} & 86.491 \\
\hline 3 & 3022.016 & 2620.387 & \multicolumn{2}{|c|}{0401.629} & 86.710 \\
\hline 4 & 0498.008 & 0422.973 & \multicolumn{2}{|c|}{0075.035} & 84.933 \\
\hline 5 & 0057.929 & 0051.445 & \multicolumn{2}{|c|}{0006.484} & 88.807 \\
\hline 6 & 0612.361 & 0456.602 & \multicolumn{2}{|c|}{0155.759} & 74.564 \\
\hline 7 & 1909.188 & 1633.565 & \multicolumn{2}{|c|}{0275.623} & 85.563 \\
\hline 8 & 8131.732 & 7550.088 & \multicolumn{2}{|c|}{0581.644} & 92.847 \\
\hline 9 & 5213.190 & 4485.441 & \multicolumn{2}{|c|}{0727.749} & 86.040 \\
\hline 10 & 1005.688 & 0662.983 & \multicolumn{2}{|c|}{0342.705} & 65.923 \\
\hline 11 & 0549.377 & 0367.389 & \multicolumn{2}{|c|}{0181.988} & 66.874 \\
\hline 12 & 0459.831 & 0068.086 & \multicolumn{2}{|c|}{0391.745} & 14.807 \\
\hline 13 & 0212.339 & 0024.842 & \multicolumn{2}{|c|}{0187.497} & 11.699 \\
\hline 14 & 4363.189 & 0473.844 & \multicolumn{2}{|c|}{3889.345} & 10.860 \\
\hline 15 & 10622.10 & 9615.273 & \multicolumn{2}{|c|}{1006.830} & 90.521 \\
\hline$\sum$ & & & \multicolumn{2}{|c|}{8376.194} & \\
\hline
\end{tabular}

Table.14. Exergy Analysis Results for Solution B

\begin{tabular}{|c|c|c|c|c|}
\hline 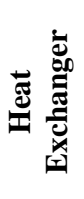 & 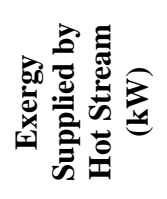 & 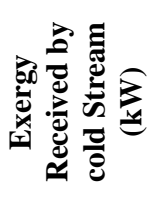 & 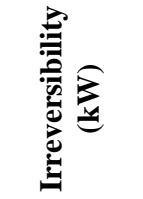 & 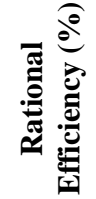 \\
\hline 1 & 2476.670 & 1373.653 & 1103.017 & 55.464 \\
\hline 2 & 4017.200 & 3440.017 & 0577.183 & 85.632 \\
\hline 3 & 0537.190 & 0397.503 & 0139.687 & 73.997 \\
\hline 4 & 1681.554 & 1094.211 & 0587.343 & 65.071 \\
\hline 5 & 0525.631 & 0489.138 & 0036.493 & 93.057 \\
\hline 6 & 1961.470 & 1781.957 & 0179.513 & 90.848 \\
\hline 7 & 1609.561 & 1282.761 & 0326.800 & 79.696 \\
\hline 8 & 0341.319 & 0259.461 & 0081.858 & 76.017 \\
\hline 9 & 1617.134 & 0674.069 & 0943.065 & 41.683 \\
\hline 10 & 7550.088 & 6892.431 & 0657.657 & 91.289 \\
\hline 11 & 0549.377 & 0367.389 & 0181.988 & 66.874 \\
\hline 12 & 0459.831 & 0068.086 & 0391.745 & 14.807 \\
\hline 13 & 0212.339 & 0024.842 & 0187.497 & 11.699 \\
\hline 14 & 4363.189 & 0473.844 & 3889.345 & 55.464 \\
\hline 15 & 10622.10 & 9615.273 & 1006.830 & 90.521 \\
\hline
\end{tabular}

\begin{tabular}{|c|c|c|c|c|}
\hline 恚 & 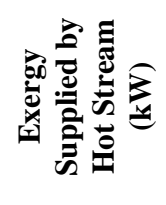 & 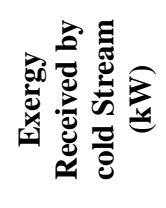 & 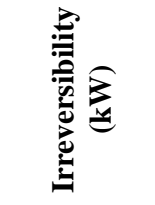 & 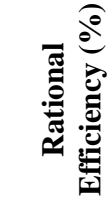 \\
\hline$\sum$ & & \multicolumn{3}{|c|}{10290.021} \\
\hline \multicolumn{5}{|c|}{ Table.15. Exergy Analysis Results for Solution C } \\
\hline 釆 & 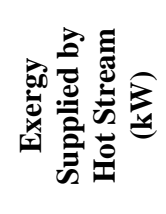 & 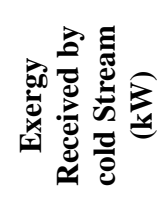 & 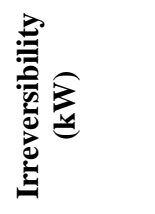 & 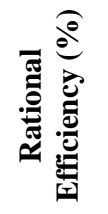 \\
\hline 1 & 2545.335 & 1633.565 & 0911.770 & 64.179 \\
\hline 2 & 2792.313 & 2055.427 & 0736.886 & 73.610 \\
\hline 3 & 7824.156 & 4536.886 & 3287.270 & 57.986 \\
\hline 4 & 2198.984 & 1986.314 & 0212.670 & 90.329 \\
\hline 5 & 1544.945 & 1431.234 & 0113.711 & 92.640 \\
\hline 6 & 4757.770 & 3838.429 & 0919.341 & 80.677 \\
\hline 7 & 0344.767 & 0127.812 & 0216.955 & 37.072 \\
\hline 8 & 1032.938 & 0950.316 & 0082.622 & 92.001 \\
\hline 9 & 0242.465 & 0160.480 & 0081.985 & 66.187 \\
\hline 10 & 0549.377 & 0367.389 & 0181.988 & 66.874 \\
\hline 11 & 0459.831 & 0068.086 & 0391.745 & 14.807 \\
\hline 12 & 0212.339 & 0024.842 & 0187.497 & 11.699 \\
\hline 13 & 4363.189 & 0473.844 & 3889.345 & 10.860 \\
\hline 14 & 10622.10 & 9615.273 & 1006.830 & 90.521 \\
\hline$\sum$ & & & 12220.615 & \\
\hline
\end{tabular}

Table.16. Exergy Analysis Results for Solution D

\begin{tabular}{|c|c|c|c|c|}
\hline 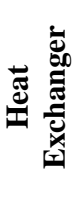 & 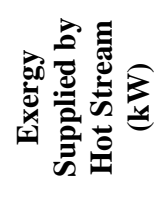 & 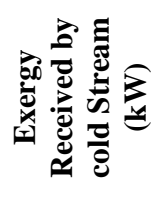 & 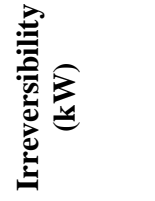 & 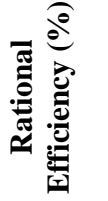 \\
\hline 1 & 4282.292 & 3578.604 & 0703.688 & 83.567 \\
\hline 2 & 5528.837 & 3158.557 & 2370.280 & 57.129 \\
\hline 3 & 1004.859 & 0841.996 & 0162.863 & 83.792 \\
\hline 4 & 3391.802 & 3237.733 & 0154.069 & 95.458 \\
\hline 5 & 1096.779 & 0601.942 & 0494.837 & 54.883 \\
\hline 6 & 1294.022 & 1124.988 & 0169.034 & 86.937 \\
\hline 7 & 1994.256 & 1378.064 & 0616.192 & 69.102 \\
\hline 8 & 1267.008 & 0717.829 & 0549.179 & 56.655 \\
\hline 9 & 1127.143 & 1045.793 & 0081.350 & 92.783 \\
\hline 10 & 1698.489 & 1633.565 & 0064.924 & 96.178 \\
\hline 11 & 0549.377 & 0367.389 & 0181.988 & 66.874 \\
\hline 12 & 0459.831 & 0068.086 & 0391.745 & 14.807 \\
\hline 13 & 0212.339 & 0024.842 & 0187.497 & 11.699 \\
\hline 14 & 4363.189 & 0473.844 & 3889.345 & 10.860 \\
\hline 15 & 10622.10 & 9615.273 & 1006.830 & 90.521 \\
\hline$\sum$ & & & 11023.821 & \\
\hline
\end{tabular}


Table.17. Irreversibility Analysis Results of Solutions

\begin{tabular}{ccccc}
\hline & \multicolumn{4}{c}{ Solution } \\
\cline { 2 - 5 } criterion & $\mathbf{A}$ & $\mathbf{B}$ & $\mathbf{C}$ & $\mathbf{D}$ \\
\hline Irreversibility & 8376.19 & 10290.02 & 12220.61 & 11023.82 \\
\hline $\operatorname{Irr}_{\text {Norm }}\left(\boldsymbol{\mu}_{\mathbf{3}}\right)$ & 0.685 & 0.842 & 1.000 & 0.902 \\
\hline
\end{tabular}

Table.18. Thermal effectiveness Results for solutions

\begin{tabular}{c|cccc}
\hline Heat & \multicolumn{4}{|c}{ Solution } \\
\cline { 2 - 5 } Exchanger & A & B & C & D \\
\hline 1 & 0.0323 & 0.2080 & 0.2581 & 0.2660 \\
2 & 0.6790 & 0.5546 & 0.1667 & 0.5374 \\
3 & 0.6225 & 0.2459 & 0.7665 & 0.1378 \\
4 & 0.1866 & 0.7858 & 0.0636 & 0.6660 \\
5 & 0.0430 & 0.1840 & 0.7500 & 0.6980 \\
6 & 0.0780 & 0.5700 & 0.7900 & 0.7190 \\
7 & 0.8300 & 0.5863 & 0.2820 & 0.2440 \\
\hline
\end{tabular}

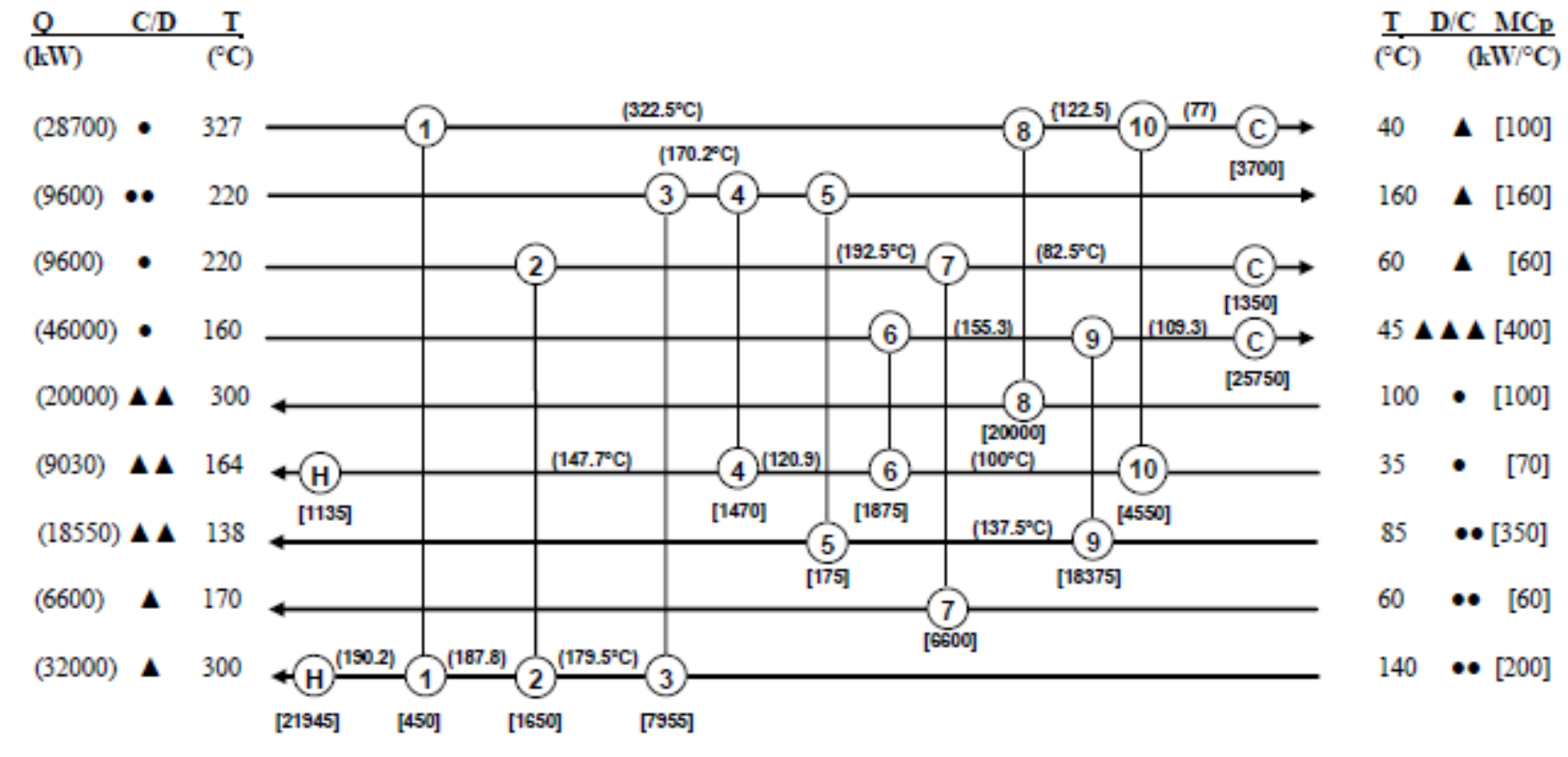

$\frac{\mathrm{T} \quad \mathrm{D} / \mathrm{C} \mathrm{MCp}}{\left({ }^{\circ} \mathrm{C}\right) \quad\left(\mathrm{kW} /{ }^{\circ} \mathrm{C}\right)}$

The summary of results of the proposed strategy is shown in Table 19, thus the optimum solution is $\mathrm{C}$ giving a high weight index of (0.435), which confirmed with results obtained.

\begin{tabular}{c|cccc}
\hline 8 & 0.8990 & 0.5420 & 0.5390 & 0.6270 \\
9 & 0.6540 & 0.1870 & 0.7650 & 0.2790 \\
10 & 0.5200 & 0.8850 & - & 0.2510 \\
\hline $\begin{array}{c}\boldsymbol{\varepsilon}_{\text {Network }} \\
\left(\boldsymbol{\mu}_{2}\right)\end{array}$ & $\mathbf{0 . 4 5 4 0}$ & $\mathbf{0 . 4 7 4 0}$ & $\mathbf{0 . 4 8 6 0}$ & $\mathbf{0 . 4 4 2 2}$
\end{tabular}

\begin{tabular}{|c|c|c|c|c|}
\hline \multicolumn{5}{|c|}{ Table.19. Fuzzy Analogical gate results } \\
\hline Solution & $\mu 1$ & $\mu 2$ & $\mu 3$ & W.I \\
\hline$\overline{\mathbf{A}}$ & 0.286 & 0.4540 & 0.685 & 0.335 \\
\hline B & 0.357 & 0.4740 & 0.842 & 0.430 \\
\hline C & 0.370 & 0.4860 & 1.000 & 0.435 \\
\hline D & 0.294 & 0.4422 & 0.902 & 0.331 \\
\hline
\end{tabular}

Fig.2. Grid diagram for solution (A) Aromatics synthesis problem 


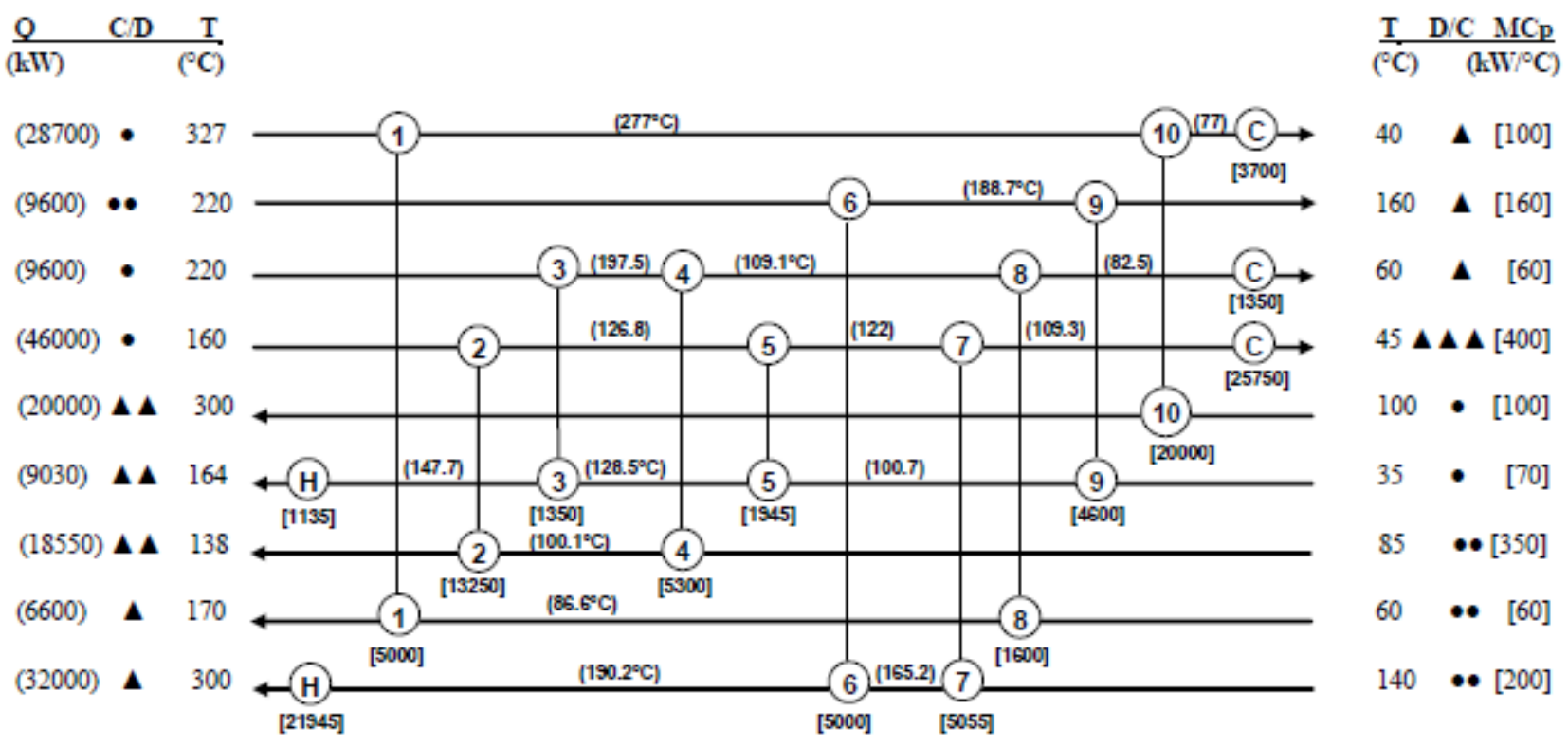

Fig.3. Grid diagram for solution (B) Aromatics synthesis problem

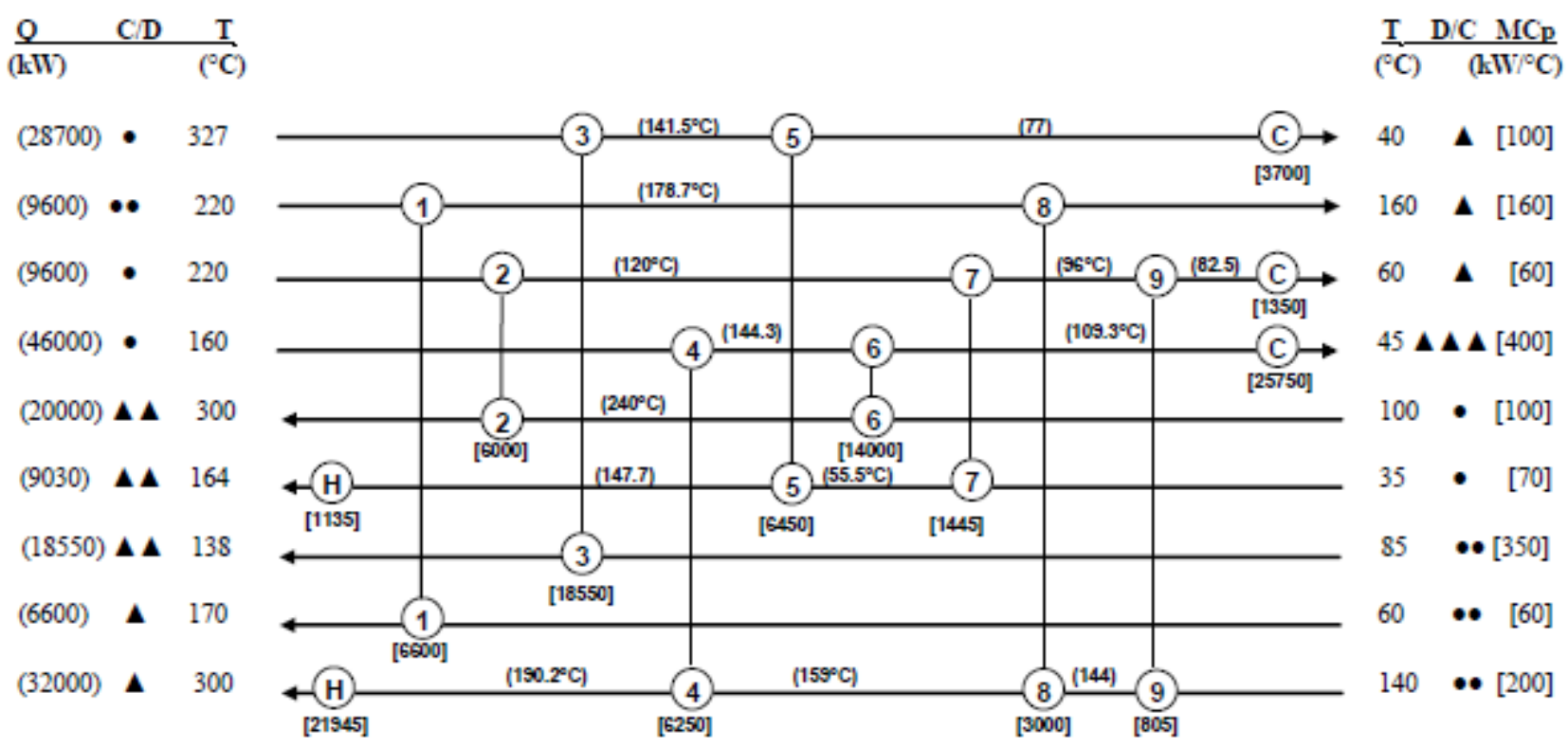

Fig.4. Grid diagram for solution (C) Aromatics synthesis problem 


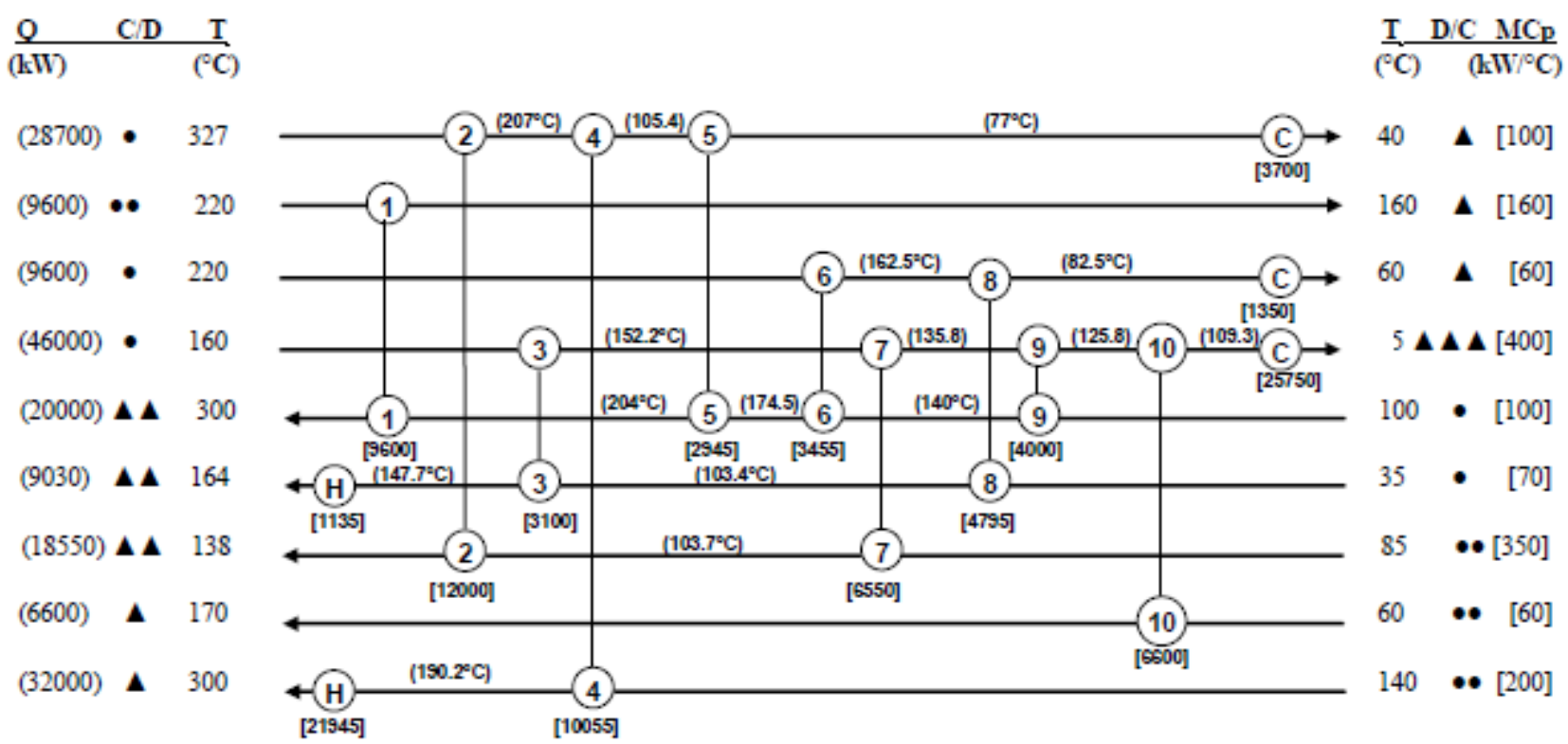

Fig.5. Grid diagram for solution (D) Aromatics synthesis problem

Table.20. Stream Data of heat exchanger network Synthesis problem H5SP1R.

\begin{tabular}{ccccc}
\hline Stream & $\begin{array}{c}\mathbf{T}_{\mathbf{i}}^{\mathbf{S}} \\
\left({ }^{\circ} \mathbf{C}\right)\end{array}$ & $\begin{array}{c}\mathbf{T}_{\mathbf{i}}^{\mathbf{t}} \\
\left({ }^{\circ} \mathbf{C}\right)\end{array}$ & $\begin{array}{c}\mathbf{M}_{\mathbf{C p i}} \\
\left(\mathbf{k W} /{ }^{\circ} \mathbf{C}\right)\end{array}$ & $\begin{array}{c}\mathbf{\delta T}_{\mathbf{i}}^{\mathbf{S}}{ }^{\mathbf{S}+)} \\
\left({ }^{\circ} \mathbf{C}\right)\end{array}$ \\
\hline $\mathbf{H 1}$ & 204.4 & 65.6 & 13.29 & 2.0 \\
$\mathbf{H 2}$ & 248.9 & 121.1 & 16.62 & 4.0 \\
$\mathbf{C 1}$ & 93.3 & 204.4 & 13.03 & 1.0 \\
$\mathbf{C 2}$ & 65.6 & 182.2 & 12.92 & 2.0 \\
$\mathbf{C 3}$ & 37.8 & 204.4 & 11.40 & 1.0 \\
\hline \multicolumn{3}{c}{ Table.21. $\mathbf{Q}$ Quantification of disturbance information } \\
\hline Stream & $\boldsymbol{\delta} \boldsymbol{Q}_{i}(\boldsymbol{k} \boldsymbol{W})$ & Degree of intensity of disturbance \\
\hline H1 & 28.94 & \multicolumn{3}{c}{ Slight disturbance } \\
H2 & 53.7 & Moderate disturbance \\
C1 & 7.475 & Slight disturbance \\
C2 & 26.47 & Slight disturbance \\
C3 & 38.58 & Moderate disturbance \\
\hline
\end{tabular}

Table.22.Quantification of level control precision information

\begin{tabular}{ccc}
\hline Stream & $\boldsymbol{\delta} \boldsymbol{T}_{i}^{\boldsymbol{t}}\left({ }^{\circ} \boldsymbol{K}\right)$ & Level of control precision) \\
\hline $\mathbf{H 1}$ & 5.5 & Low control precision \\
$\mathbf{H 2}$ & 3.0 & Moderate control precision \\
$\mathbf{C 1}$ & 6.0 & Low control precision \\
$\mathbf{C 2}$ & 7.0 & Low control precision \\
$\mathbf{C 3}$ & 1.0 & High control precision \\
\hline
\end{tabular}

Table.23. Represent the comparison of the Solutions for Heat Exchanger Network Problem H5SP1R, this popular example has been studied in many researches and by different strategies [9, 12 and 22], such as distributed strategy which is an artificial intelligence approach for incorporation of controllability into process design; knowledge engineering approach to the incorporation of controllability into exchanger network synthesis; HIDEN which is an implementation of a distributed strategy for integrating process design and control. It has been found that solution (A) gives high index of structural controllability. Now let's examine the proposed

\begin{tabular}{ccccc}
$\begin{array}{c}\delta \mathbf{T}_{\mathbf{i}}{ }^{\mathbf{S}(-)} \\
\left({ }^{\circ} \mathbf{C}\right)\end{array}$ & $\begin{array}{c}\delta \mathbf{M}_{\mathbf{C p i}{ }^{(+)}} \\
\left(\mathbf{k W} /{ }^{\circ} \mathbf{C}\right)\end{array}$ & $\begin{array}{c}\delta \mathbf{M}_{\mathbf{C p i}{ }^{(-)}} \\
\left(\mathbf{k W} /{ }^{\circ} \mathbf{C}\right)\end{array}$ & $\begin{array}{c}\boldsymbol{\delta} \mathbf{T}_{\mathbf{i}}{ }^{\mathbf{t}} \\
\left({ }^{\circ} \mathbf{C}\right)\end{array}$ & $\begin{array}{c}\mathbf{Q}_{\mathbf{i}} \\
(\mathbf{k W})\end{array}$ \\
\hline 2.0 & 0.4 & 0.4 & 5.5 & 1884.7 \\
3.0 & 0.1 & 0.2 & 3.0 & 2124.0 \\
0.6 & 0.05 & 0.1 & 6.0 & 1447.6 \\
2.5 & 0.1 & 0.05 & 7.0 & 1506.5 \\
3.0 & 0.3 & 0.4 & 1.0 & 1899.2 \\
\hline
\end{tabular}

strategy on this example. Tables $24,25,26,27,28$ and 29
show the exergy analysis and normalized irreversibility results. The thermal effectiveness for solutions A, B, C, D and E is shown in Table 30.

Table.23. Comparison of the Solutions for Heat Exchanger Network Synthesis Problem H5SP1R

\begin{tabular}{lc|ccc}
\hline \multirow{2}{*}{ Criterion } & Solution & \multicolumn{3}{|c}{ Authors } \\
\cline { 3 - 5 } & & $\begin{array}{c}\text { Huang } \\
{[\mathbf{9 ]}}\end{array}$ & $\begin{array}{c}\text { Huang } \\
{[\mathbf{1 2}]}\end{array}$ & $\begin{array}{c}\text { Huang } \\
{[22]}\end{array}$ \\
\hline \multirow{2}{*}{ Strategy } & & D.S. (A.I) & D. S. & HIDEN \\
MER $(\mathrm{kW})$ & & 884.6 & 884.6 & 884.6 \\
NTU & & 5 & 5 & 5 \\
& $\mathbf{A}$ & $\mathbf{0 . 4 6 2}$ & $\mathbf{0 . 9 5 8}$ & $\mathbf{0 . 9 5 8}$ \\
& $\mathrm{B}$ & 0.429 & 0.917 & 0.917 \\
I $_{\text {SC }}\left(\boldsymbol{\mu}_{\mathbf{1}}\right)$ & $\mathrm{C}$ & 0.263 & 0.750 & 0.750 \\
& $\mathrm{D}$ & 0.172 & 0.083 & 0.083 \\
& $\mathrm{E}$ & 0.172 & 0.083 & 0.083 \\
\hline
\end{tabular}

Table.24. Exergy Analysis Results for Solution A

\begin{tabular}{|c|c|c|c|c|}
\hline 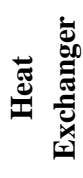 & 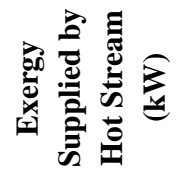 & 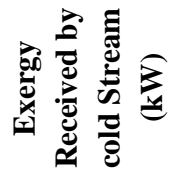 & 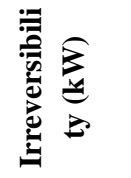 & 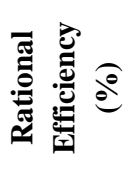 \\
\hline 1 & 230.934 & 182.100 & 048.834 & 078.850 \\
\hline 2 & 289.645 & 260.039 & 029.605 & 089.770 \\
\hline 3 & 567.456 & 446.637 & 120.819 & 078.700 \\
\hline 4 & 202.671 & 137.764 & 064.907 & 067.970 \\
\hline 5 & 393.625 & 298.174 & 095.451 & 075.750 \\
\hline
\end{tabular}




\begin{tabular}{|c|c|c|c|c|}
\hline$\sum$ & & \multicolumn{3}{|c|}{359.616} \\
\hline \multicolumn{5}{|c|}{ Table.25. Exergy Analysis Results for Solution B } \\
\hline 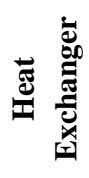 & 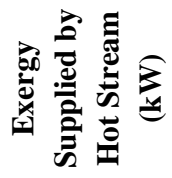 & 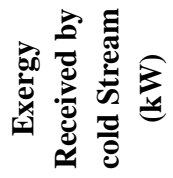 & 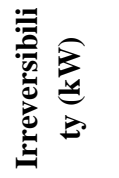 & 苞 氖 \\
\hline 1 & 508.678 & 397.736 & 110.942 & 078.190 \\
\hline 2 & 230.934 & 182.100 & 048.834 & 078.850 \\
\hline 3 & 289.645 & 245.507 & 044.138 & 084.760 \\
\hline 4 & 261.536 & 222.441 & 039.095 & 085.050 \\
\hline 5 & 393.625 & 298.174 & 095.451 & 075.750 \\
\hline $\bar{\Sigma}$ & & & 338.430 & \\
\hline
\end{tabular}

Table.26. Exergy Analysis Results for Solution C

\begin{tabular}{|c|c|c|c|c|}
\hline 离 & 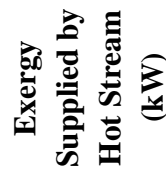 & 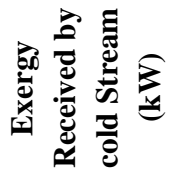 & 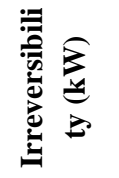 & 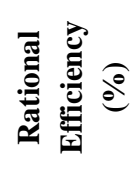 \\
\hline 1 & 058.890 & 036.814 & 022.076 & 062.513 \\
\hline 2 & 202.671 & 145.325 & 057.346 & 057.346 \\
\hline 3 & 461.671 & 397.730 & 063.941 & 086.150 \\
\hline 4 & 567.450 & 421.539 & 145.911 & 074.280 \\
\hline 5 & 393.625 & 298.174 & 095.451 & 075.750 \\
\hline$\sum$ & & & 384.725 & \\
\hline
\end{tabular}

Table.27. Exergy Analysis Results for Solution D

\begin{tabular}{|c|c|c|c|c|}
\hline 离 & 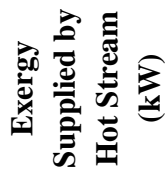 & 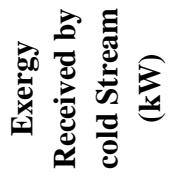 & 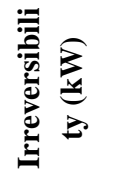 & 氞 \\
\hline 1 & 058.890 & 036.814 & 022.076 & 065.510 \\
\hline 2 & 461.671 & 397.736 & 063.930 & 086.150 \\
\hline 3 & 604.745 & 443.528 & 161.217 & 073.341 \\
\hline 4 & 165.572 & 141.656 & 023.916 & 085.550 \\
\hline 5 & 375.826 & 304.969 & 070.857 & 081.140 \\
\hline$\sum$ & & & 341.996 & \\
\hline
\end{tabular}

Table.28. Exergy Analysis Results for Solution E

\begin{tabular}{|c|c|c|c|c|}
\hline 㷰 & 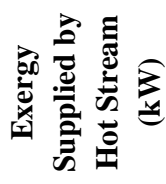 & 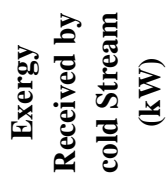 & 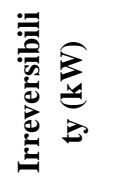 & 氞 \\
\hline 1 & 316.203 & 261.523 & 054.680 & $\overline{082.700}$ \\
\hline 2 & 204.850 & 141.656 & 063.194 & 069.150 \\
\hline 3 & 260.435 & 218.720 & 041.715 & 083.980 \\
\hline 4 & 507.932 & 397.736 & 110.196 & 078.300 \\
\hline 5 & 393.625 & 304.969 & 088.650 & 077.470 \\
\hline $\bar{\Sigma}$ & & & 358.430 & \\
\hline
\end{tabular}

Table.29. Irreversibility Analysis Results of Solutions

\begin{tabular}{cccccc}
\hline & \multicolumn{5}{c}{ Solution } \\
\cline { 2 - 6 } criterion & $\mathbf{A}$ & $\mathbf{B}$ & $\mathbf{C}$ & $\mathbf{D}$ & $\mathbf{E}$ \\
\hline Irr. $(\mathrm{kW})$ & 359.6 & 338.4 & 384.7 & 341.9 & 358.4 \\
\hline Irr $_{\text {Norm. }}\left(\boldsymbol{\mu}_{3}\right)$ & 0.934 & 0.879 & 1.000 & 0.888 & 0.931 \\
\hline \multicolumn{6}{c}{ Solution } \\
\multicolumn{6}{c}{ Table.30. Thermal effectiveness Results for solutions } \\
\hline $\begin{array}{c}\text { Heat } \\
\text { Exchanger }\end{array}$ & $\mathbf{A}$ & $\mathbf{B}$ & $\mathbf{C}$ & $\mathbf{D}$ & $\mathbf{E}$ \\
\cline { 2 - 6 } 1 & 0.732 & 0.620 & 0.477 & 0.477 & 0.776 \\
2 & 0.723 & 0.732 & 0.430 & 0.817 & 0.381 \\
3 & 0.560 & 0.562 & 0.817 & 0.517 & 0.384 \\
4 & 0.422 & 0.404 & 0.560 & 0.549 & 0.618 \\
\hline $\boldsymbol{\varepsilon}_{\text {Network }}$ & $\mathbf{0 . 6 0 9}$ & $\mathbf{0 . 5 7 9}$ & $\mathbf{0 . 5 7 1}$ & $\mathbf{0 . 5 9 0}$ & $\mathbf{0 . 5 3 9}$ \\
\hline
\end{tabular}

By applying the proposed strategy for Huang [9], [12] and [22]; it has been found that solution A gives the highest weight index (0.5665) and (0.7259) respectively as shown in Tables 31 and 32 .

Table.31. Fuzzy Analogical gate results for Huang [9].

\begin{tabular}{ccccc}
\hline Solution & $\boldsymbol{\mu}_{\mathbf{1}}$ & $\boldsymbol{\mu}_{\mathbf{2}}$ & $\boldsymbol{\mu}_{\mathbf{3}}$ & $\boldsymbol{W} . \mathbf{I}$ \\
\hline $\mathbf{A}$ & 0.462 & 0.609 & 0.934 & $\mathbf{0 . 5 6 6 5}$ \\
$\mathbf{B}$ & 0.429 & 0.579 & 0.879 & 0.5247 \\
$\mathbf{C}$ & 0.263 & 0.571 & 1.000 & 0.2246 \\
$\mathbf{D}$ & 0.172 & 0.590 & 0.888 & 0.0784 \\
$\mathbf{E}$ & 0.172 & 0.539 & 0.931 & 0.0865 \\
\hline
\end{tabular}

Table.32. Fuzzy Analogical gate results for Huang [12] and [22]

\begin{tabular}{ccccc}
\hline Solution & $\boldsymbol{\mu}_{\mathbf{1}}$ & $\boldsymbol{\mu}_{\mathbf{2}}$ & $\boldsymbol{\mu}_{\mathbf{3}}$ & $\boldsymbol{W} . \mathbf{I}$ \\
\hline $\mathbf{A}$ & 0.958 & 0.609 & 0.934 & $\mathbf{0 . 7 2 5 9}$ \\
$\mathbf{B}$ & 0.917 & 0.579 & 0.879 & 0.6884 \\
$\mathbf{C}$ & 0.750 & 0.571 & 1.000 & 0.6994 \\
$\mathbf{D}$ & 0.083 & 0.590 & 0.888 & 0.0126 \\
$\mathbf{E}$ & 0.083 & 0.539 & 0.931 & 0.0139 \\
\hline
\end{tabular}

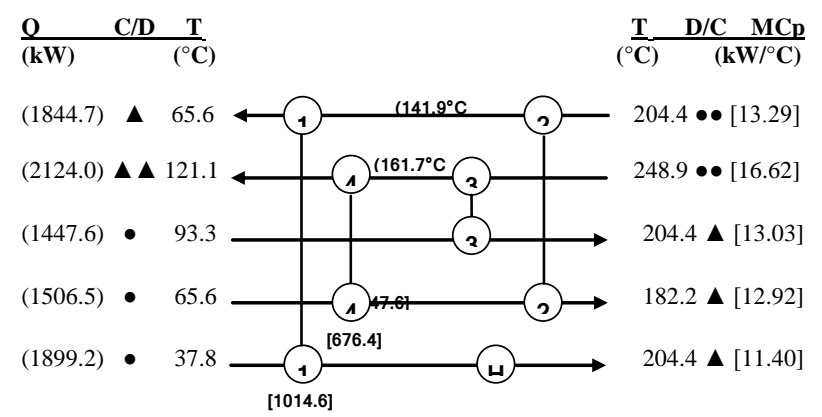

Fig.6. Grid diagram for solution (A) HEN synthesis problem H5SP1R

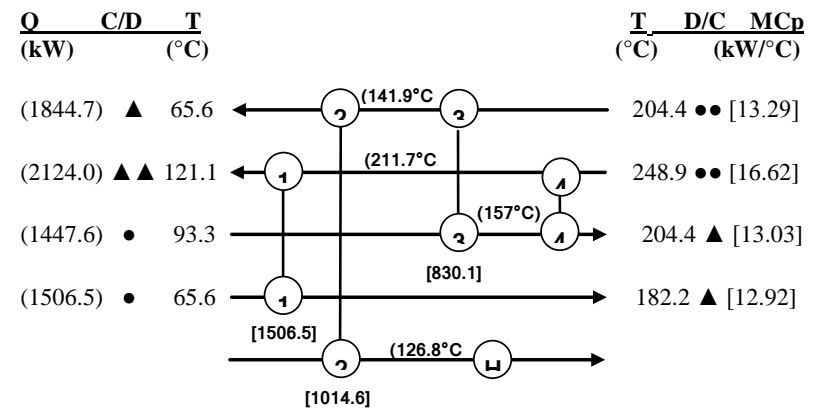


Fig.7. Grid diagram for solution (B) HEN synthesis problem H5SP1R

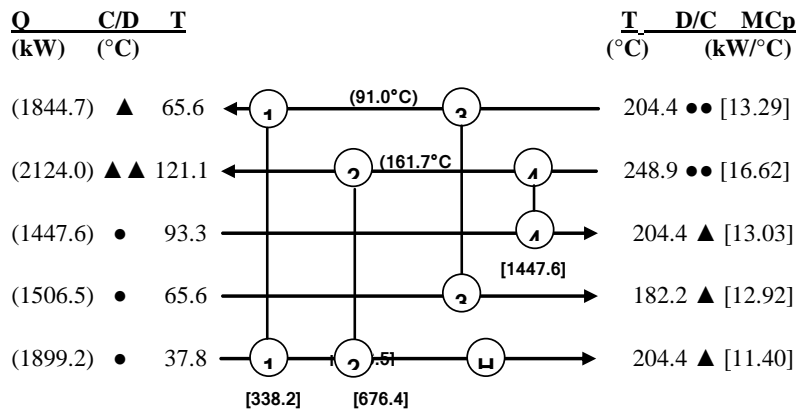

Fig.8. Grid diagram for solution (C) HEN synthesis problem H5SP1R

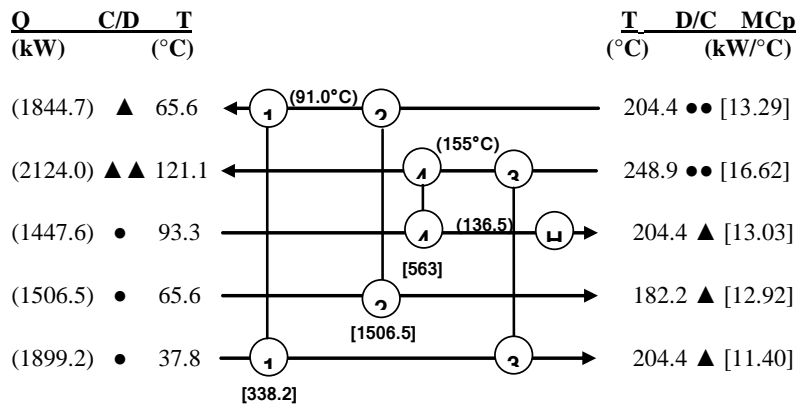

Fig.9. Grid diagram for solution (D) HEN synthesis problem H5SP1R

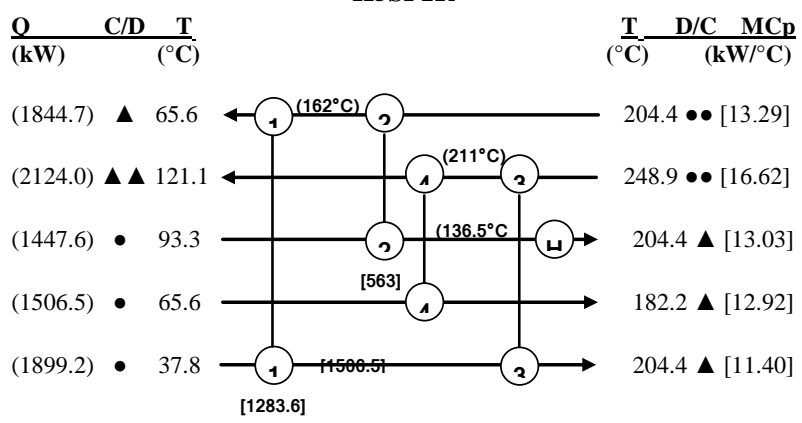

Fig.10. Grid diagram for solution (E) HEN synthesis problem H5SP1R

\section{CONCLUSIONS}

The present study explores new strategy for synthesis optimum controllable heat exchanger network. The proposed strategy consists of four sequential steps: i) Quantification of index of structural controllability. ii) Exergy analysis and normalized irreversibility. iii) Thermal effectiveness of network. iv) Fuzzy analogical gates network and selection of the best weight index. Two analogical gates are employed. The symmetric gate (AND gate) inputs are the index controllability and thermal effectiveness. The asymmetric gate (Invoke gate) inputs are the output of the AND gate and the normalized irreversibility. It has been found that when applied to problems previously reported in the literature yielded optimum solutions which are consistent with different approach, such as Artificial Intelligence, Knowledge Engineering Approach and Hybrid Intelligent System. It is evident that the performance of the index of structural controllability, normalized irreversibility, thermal effectiveness and Fuzzy analogical gates is quite encouraging, accurate in taking decision to design optimum controllable HEN's.

\section{Nomenclature}

A.I

C

$\mathrm{C}^{*}$

$\mathrm{c}_{\mathrm{j}}$

$\mathrm{C}_{\mathrm{h}}$

$\mathrm{C}_{\mathrm{c}}$

CA

DS

D

DP

di

$E_{\text {tot }}$

ESDU

HENs

HTU's

HIDEN

Ir $r_{\text {Normalized }}$

$I_{S C}$

K.A

MER

$M_{C p i}$

$\mathrm{N}$

NTU

$P$

$P_{i, j}$

$Q$

$Q_{\max }$

$\mathrm{Q}_{\mathrm{i}}$

$\mathrm{T}_{0}$

$\mathrm{T}_{\mathrm{AM}}$

$\mathrm{T}_{\mathrm{i}}^{\mathrm{t}}$

W.I

$\varepsilon_{\mathrm{NW}}$

$\eta_{U}$

$\eta_{f}$

$\mu_{1}$

$\mu_{2}$

$\mu_{3} \delta T_{i}^{S(+)}$

$\delta T_{i}^{S(-)}$

$\delta M_{C p i}^{(+)}$

$\delta M_{C p i}^{(-)}$

$\delta T_{i}^{t}$
Artificial Intelligence

Control Precision vector the thermal capacity of stream

Element of control precision vector C, representing control precision of stream $j$

Thermal capacity ratio of hot stream

Thermal capacity ratio of cold stream

The controllability assessment

Distributed Strategy

Disturbance vector

Disturbance Propagation

Element of disturbance vector D, representing the disturbance source of stream $i$

Effects of all patterns of disturbance propagation on the controllability of stream $j$ Effects of all patterns of disturbance propagation on the controllability of a process Engineering Sciences Data Unit

Heat Exchanger Networks

Heat Transfer Units.

Hybrid Intelligent System

Normalized irreversibility

Index of structural controllability

Knowledge Approach

Minimum energy requirements

Heat capacity flowrate of stream $i$

Total number of streams in a process

The number of heat transfer units

Disturbance propagation matrix

Element of disturbance propagation matrix $\mathrm{P}$, representing disturbance propagation from the inlet of stream $i$ to the outlet of stream $j$ The amount of actually heat transferred

The maximum amount of theoretically transferable heat.

Heat duty of stream i

Ambient Temperature

Logarithmic mean temperature difference

Source temperature of stream $i$

Target temperature of stream $i$

Weight Index

Thermal effectiveness of network

The universal efficiency

The functional efficiency

First AND gate input

Second AND gate input

Invoke gate input

Maximum deviation of the source temperature of stream $i$ in the positive direction

Maximum deviation of the source temperature of stream $i$ in the negative direction

Maximum deviation of the heat capacity

flowrate of stream $i$ in the positive direction

Maximum deviation of the heat capacity

flowrate of stream $i$ in the negative direction

Maximum allowable deviation of target 


$\begin{array}{ll}\delta Q_{i} & \begin{array}{l}\text { temperature of stream } i \\ \text { Maximum absolute value of the deviation of } \\ \text { the heat duty of stream } i \\ \text { the specific exergy }\end{array} \\ \Delta \mathrm{Ex} & \begin{array}{l}\text { Exergy Supplied by Hot Stream } \\ \Delta \mathrm{Ex}]_{\text {Hot }}\end{array} \\ \Delta \mathrm{Ex}]_{\text {Cold }} & \begin{array}{l}\text { Exergy Received by cold Stream } \\ \text { the specific enthalpy }\end{array} \\ \Delta \mathrm{H} & \text { the specific entropy } \\ \Delta \mathrm{S} & \\ \text { Superscripts } & \text { Source } \\ \mathrm{S} & \text { Target } \\ \mathrm{t} & \\ \text { Subscripts } & \\ i & \text { Stream } i \\ \mathrm{j} & \text { Stream } j\end{array}$

\section{REFERENCES}

[1] Douglas J. M. 1982. Process Operability and Control of Preliminary Designs. In chemical Process Control- II (Edgar T. and Seborg D. E., Eds); Engineering Foundation, New York.

[2] McAvoy T. J. 1983. Interaction Analysis: Principles and Applications. Instrument society of America, Research Triangle Park, NC.

[3] Shinskey F. G. 1983. Uncontrollable Processes and What to do about them. Hydrocarbon Process. Volume 62

[4] Calandranis J. and Stephanopoulos, G. 1986. "Structural Operability of Heat Exchangers Networks", Chemical Engineering Research and Design. Volume 64, (Sept. 1986), 347-364.

[5] Fisher W. R., Doherty M. F. and Douglas J. M. 1988."The interface between Design and Control".1. Process Controllability, Industrial and Engineering Chemistry Research. Volume 27, (1988a), 596-605.

[6] Fisher W.R., Doherty M. F. and Douglas J. M. 1988. "The interface between Design and Control".2. Process Operability, Industrial and Engineering Chemistry Research. Volume 27, (1988b), 606-611.

[7] Huang Y. L. and Fan L.T. 1988. An Application of Knowledge Engineering: "Conceptual Analysis of Controllability in Synthesizing a Heat Exchanger Network". Presented at the Fourth Pacific Chemical Engineering Congress; Acapulco, Mexico.

[8] Huang Y. L. and Fan L.T. 1988. "Strategy for Enhancing Structural Controllability in Heat Exchanger Network Synthesis", a Knowledge Engineering Approach. Presented at AIChE Annual Meeting (Paper No.81f, 1988b), Washington, DC.

[9] Huang Y. L. and Fan L.T. 1989 "A Distributed Strategy for Integration of Process Design and Control”: An Artificial Intelligence Approach for Incorporation of Controllability into Process Design. Presented at AIChE Annual Meeting (Paper No.27e), (1989), San Francisco, California.
[10] Kalman, R. E. 1990. Contributions to the theory of optimal control. Bol. Soc. Mater. Mexico, 5, 102-119.

[11] Line C.T. 1974. Structural Controllability. IEEE Trans. Automatic Control. 19, 201-208

[12] Huang, Y. L. and Fan L. T. 1992. "A Distributed Strategy for Integration of Process Design and Control. A Knowledge Engineering Approach to the Incorporation of Controllability into Exchanger Network Synthesis", Computers and Chemical Engineering. Volume 16, No. 5, 497-522.

[13] Linnhoff, B. and Kotjabasakis, E. 1986. "Downstream paths for operable process design", Chemical Engineering Progress, (May 1986), 23-28.

[14] ESDU International plc, London. 1998. DATA ITEMS 98003/4/5/6: "Design and Performance Evaluation of Heat Exchangers: The Effectiveness-NTU method".

[15] Kays W. M., London A. L. 1984. "Compact heat exchangers", Third Edition, Krieger Publishing Company. Malabar, Florida.

[16] Picon N. M. and Polley, G. T. 1995. "Determination of the Steady State Response of Heat Exchanger Networks without Simulation", Trans IChemE. Volume 73, (Jan.1995), Part A, 49-58.

[17] Abu-Khader M. M. 1997. "Control strategies for steady state operation of two stream heat exchangers", $P h D$ Thesis, UMIST, U. K.

[18] Fidel V. G. 2003. "Control Strategies for Flexible Heat Exchanger Networks". PhD Thesis, UMIST, U. K. (July 2003)

[19] Predrag R., Gradimir I., Nenad R., Mića V., Goran V., Dragan K. 2002. "Process Integration Exergy Loses of the Heat Exchanger Networks FACTA Universities Series; Mechanical Engineering. Volume 1, No 9, 1253 1261.

[20] Hussein M.H., Moselhy H., Aly S., Awad M. E. 2013. "Fuzzy Analogical Gates Approach for Heat Exchangers Networks" International Journal of Computer Applications. Volume 73- No.21, (July 2013), $1-8$.

[21] Ian.C. Kemp., 'Pinch Analysis and Process integration A user guide on process integration for the efficient use of energy"' (2007)., (II edition) British Library.

[22] Huang, Y. L. and Fan, T. L. 1994. "HIDEN: A Hybrid Intelligent System for Synthesizing Highly Controllable Exchanger Networks. Implementation of a Distributed Strategy for Integrating Process Design and Control", Industrial and Engineering Chemistry Research. Volume 33, No. 5, 1174-1187. 